\title{
La producció dels sons oclusius del català per part dels aprenents sinòfons: estudi contrastiu, anàlisi d'errors i propostes de millora ${ }^{1}$
}

\author{
Liyun Wang \\ rocioadeline@gmail.com
}

Rebut: 22 de maig del 2020

Acceptat: 10 de setembre del 2020

\section{Resum}

Aquesta contribució s'insereix en el camp de la didàctica de la llengua catalana com a llengua estrangera $i$, més concretament, en el de la fonologia contrastiva. Es contrasten els fonemes oclusius del català $i$ el xinès estàndard - putonghuà2 — en l'àmbit segmental i el suprasegmental sillàbic (distribució en la síllaba) per tal de preveure les dificultats que han d'afrontar els sinoparlants abans de dominar la pronunciació dels sons oclusius i aproximants del català. L'estudi de camp es basa en la producció de /p-b/, /t-d/, /k-g/ del català per part de 19 estudiants universitaris d'origen xinès de 20-35 anys que residien a l'àrea metropolitana de Barcelona. Es parteix d'un corpus format per 115 mots o compostos amb /p-b/, /t-d/ i / k-g/ en diferents posicions sil.làbiques (obertura simple o complexa a l'inici o interior de mot, coda simple o complexa a l'interior o al final de mot), a fi de poder realitzar un estudi com més ampli possible dels tipus d'errors o imprecisions que poden presentar els aprenents xinesos. Basant-se en els errors detectats, es proposen estratègies didàctiques per millorar la pronunciació dels aprenents sinòfons.

\section{Paraules clau}

Català, oclusius, sord, sonor, xinès

\begin{abstract}
This contribution is inserted in the field of teaching Catalan language as a foreign language and, more specifically, in contrastive phonology. The paper contrasts plosive phonemes of Catalan and Standard Chinese - Putonghua - in segmental and suprasegmental syllabic (syllable distribution) domains in order to anticipate the difficulties that Chinese L1speakers must face before mastering the pronunciation of plosive and approximant sounds in Catalan. The research is based on the production of /p-b/, /t-d /, /k-g/ in Catalan by 19 university students of Chinese origin aged 2035 living in the urban area of Barcelona. The analyzed corpus consists of 115 words or compounds with /p-b/, /t-d/ and / k-g/ in different syllabic positions (simple or complex opening at the beginning or inside of a word, simple or complex coda inside or at the end of a word), in order to be able to carry out a study encompassing as much as possible the different types of errors or inaccuracies that Chinese learners may present when speaking Catalan. Based on the errors that we detected, didactic strategies are proposed to improve the pronunciation of these learners.
\end{abstract}

\section{Key words}

Catalan, Chinese, plosive, voiced, voiceless

1 Aquest treball deriva dels estudis de la tesi doctoral "Estudi contrastiu de l'estructura sil-làbica del català i del xinès estàndards i de les implicacions segmentals més rellevants per als aprenents sinòfons". Disponible a: https://www.tdx.cat/handle/10803/666220\#page=1

2 Els termes xinesos es transfereixen mitjançant el sistema alfabètic llatinitzat pinyin, destonalitzats i adaptats al català, amb pronúncia generalment oxítona. 


\section{Introducció}

\subsection{Motiu de recerca}

La població xinesa als Països Catalans està creixent i s'ha convertit en una comunitat important de la societat catalana. Segons les dades proporcionades per l'Institut d'Estadística de Catalunya (IDESCAT) sobre la població estrangera empadronada a Catalunya, el nombre d'habitants d'origen xinès ha anat creixent des de l'any 2000, i entre el 2014 i el 2019 va mantenir el tercer lloc entre tots els països registrats, precedit per Marroc i Romania.

Figura 1. Evolució de la població xinesa empadronada a Catalunya entre 2000 i $2019^{3}$

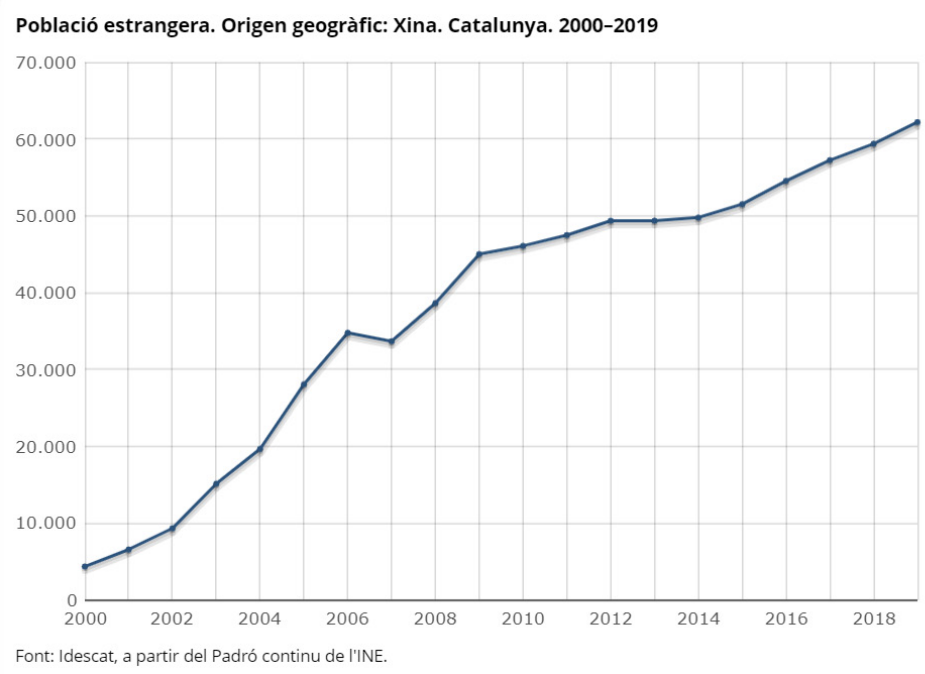

A més dels comerciants xinesos que resideixen a les terres de parla catalana des de fa molts anys, en els darrers anys ha augmentat a un ritme significatiu el nombre d'estudiants xinesos que arriben per estudiar a la universitat. Les dades de la taula següent, extretes del Portal d'Immigració d'Espanya, mostren com va mantenir la tendència de creixement entre el 2014 i el 2019 el nombre dels estudiants de la Xina i de Taiwan residents a Catalunya amb autorització d'estada per estudis en vigor.

Taula 1. Nombre d'estudiants de la Xina i de Taiwan a Catalunya amb autorització d'estada entre el 2014 i el $2019^{4}$

\begin{tabular}{|l|l|l|}
\hline Data & Xina & Taiwan \\
\hline $31 / 03 / 2014$ & 1.075 & 59 \\
$30 / 06 / 2014$ & 1.020 & 36 \\
$30 / 09 / 2014$ & 712 & 43 \\
$31 / 12 / 2014$ & 1.128 & 56 \\
$30 / 06 / 2015$ & 993 & 47 \\
$31 / 12 / 2015$ & 891 & 39 \\
$30 / 06 / 2016$ & 1.022 & 45 \\
$31 / 12 / 2016$ & 1.559 & 86 \\
\hline
\end{tabular}

3 Font: https://www.idescat.cat/poblacioestrangera/?b=0\&nac $=\mathrm{d} 407$

4 Font: http://extranjeros.inclusion.gob.es/es/Estadisticas/operaciones/con-autorizacion/index.html. 


\begin{tabular}{|l|l|l|}
\hline $30 / 06 / 2017$ & 1.471 & 65 \\
$31 / 12 / 2017$ & 1.620 & 111 \\
$30 / 06 / 2018$ & 1.790 & 83 \\
$31 / 12 / 2018$ & 1.723 & 117 \\
$30 / 06 / 2019$ & 1.904 & 111 \\
\hline
\end{tabular}

Mentrestant, aquesta població oriental ha mostrat cada cop més interès per la llengua catalana. D'una banda, els fills dels immigrants xinesos que s'han escolaritzat aquí tenen un cert nivell de català. De l'altra, una bona part dels estudiants universitaris han fet uns cursos bàsics del català a la universitat o al Consorci per a la Normalització Lingüística (CNPL); alguns d'aquests, s'animen a aprofundir en l'aprenentatge per motius acadèmic, de relació social o purament per interès personal. També cal esmentar que a la Xina hi ha més gent que mai interessada a conèixer el català atreta per la ciutat de Barcelona i el seu club de futbol. La Universitat d'Estudis Estrangers de Beijing va obtenir l'autorització d'oferir la carrera de la llengua catalana i ha impartit assignatures d'aquest idioma en colllaboració amb l'Institut Ramon Llull. La Universitat d'Estudis Estrangers de Guangdong també ha ofert conferències d'introducció a la llengua i cultura catalanes. Aquests fenòmens indiquen una tendència que podria ser un motiu suficient per realitzar estudis acadèmics sobre la didàctica de la llengua catalana per als sinoparlants; i la fonologia, o més ben dit l'ensenyament de la pronunciació, mereix una atenció capital, ja que la bona pronunciació és bàsica per a la comunicació i la integració social.

\subsection{Objectius i marc teòric}

Aquest treball té l'objectiu de contrastar els fonemes oclusius del català i el xinès estàndard ${ }^{5}$ per tal de preveure les dificultats que han d'afrontar els parlants nadius del xinès a l'hora d'aprendre els sons oclusius i aproximants espirants del català, així com els tipus d'errors que poden presentar. Aquesta part s'assoleix en la teoria d'anàlisi contrastiva i la noció de transferència lingüística. També té l'objectiu de recollir i analitzar els errors o imprecisions de pronunciació que presenten els aprenents sinòfons, per tal de comprovar els resultats de previsió obtinguts en la part de contrast, així com localitzar els tipus d'errors que no es poden preveure basant-se en l'anàlisi contrastiva. Aquesta part s'assoleix en la teoria d'anàlisi d'errors. En analitzar els errors, també es té en compte la noció d'interllengua.

\subsection{Metodologia emprada}

\section{Contrast fònic}

En la part d'anàlisi contrastiva, es realitza contrast fònic dels sons oclusius i aproximants espirants del català i del xinès a partir de l'AFI i el pinyin (el sistema de romanització de l'idioma xinès). També es té en compte la distribució en la sílllaba d'aquests sons en les dues llengües.

5 D'ara endavant es refereix al xinès estàndard simplement com a xinès. El xinès, en termes generals, més que una llengua constitueix una família d'idiomes sinítics utilitzats a la República Popular de la Xina — d'ara endavant ens hi referim com a Xina-, Hong Kong, Taiwan, Malàisia i Singapur, entre altres. Es poden classificar en els següents grups: guanhuà (literalment, 'parla dels mandataris'), wu (per exemple el shanghaihuà), yue (per exemple el guangdonghuà), hakka, xiang, gan i min (com ara el taiwanhuà). Aquestes varietats que tradicionalment es consideraven dialectes sovint no són mútuament intel·ligibles. A més del xinès, a la Xina també s'utilitzen unes llengües no sinítiques per part de menys del 10\% de la població, com ara l'uigur, el tibetà, el mongol, llengües del grup tai i el coreà, etc. Com està disposat en Instruccions del Consell d'Estat de la República Popular de la Xina sobre la promulgació de putonghuà del 1956 (国务院关于推广普通话的指示), aquesta gran diversitat lingüística, havent perjudicat greument la comunicació entre persones de diferents zones i el desenvolupament de la política, l'economia, cultura i defensa nacionals, va donar lloc a l'estandardització del xinès i la codificació del putonghuà (literalment, 'parla comuna'). El putonghuà es basa al dialecte del nord, l'anomenat "mandarí", i pren com a normes la pronunciació de Pequín i la gramàtica del xinès escrit vernacle. 


\section{La gradació de prioritats d'actuació metodològica}

No tots els problemes de pronunciació s'han de tractar amb la mateixa prioritat. Seguint el mètode que prenen Kenworthy (1987, p. 123) i Julià-Muné (2005), es classifiquen els errors de pronunciació en tres nivells: prioritat alta (PA), prioritat baixa $(\mathrm{PB})$ i atenció esporàdica (AE). Els problemes de PA són les desviacions bàsiques per a la intel-ligibilitat, com ara la no distinció de sonoritat: $[\mathrm{b}, \mathrm{d}, \mathrm{g}]>$ xinès ${ }^{*}[\mathrm{p}, \mathrm{t}, \mathrm{k}]$; els de $\mathrm{PB}$ són les imprecisions que no afectin la intel-ligibilitat, per exemple, la manca d'aproximantització: $[\beta, \delta, \gamma]>$ xinès ${ }^{\star}[b, d, g]$; els problemes que indiquin accents estrangers però no causin problemes d'intel-ligibilitat es consideren d'AE, com ara la manca d'assimilació Casa $B a[\mathrm{~d} . K]$.

\section{Estudi contrastiu d'inventari i previsió de problemes}

\subsection{Tres tipus d'oclusius}

En aquest treball s'impliquen tres tipus d'oclusius: tres sords no aspirats /p, t, k/, tres sords aspirats $/ \mathrm{p}^{\mathrm{h}}, \mathrm{t}^{\mathrm{h}}, \mathrm{k}^{\mathrm{h}} / \mathrm{i}$ tres sonors no aspirats $/ \mathrm{b}, \mathrm{d}, \mathrm{g} /$. Els dos grups de sords existeixen en xinès; en català, castellà $i$ anglès hi ha el grup de sords no aspirats i el de sonors, mentre en aquest últim els sons aspirats són al-lòfons dels no aspirats corresponents perquè es troben en distribució complementària (McMahon, 2002: $\$ 2.4$ i $\$ 9.5$ ).

Aquests sons s'anomenen oclusius perquè en emetre's hi ha un procés de desclosió quan el flux d'aire trenca l'oclusió formada pels òrgans articulatoris en contacte. Abans de la desclosió, la glotis està oberta. La diferència entre els sords no aspirats $/ \mathrm{p}, \mathrm{t}, \mathrm{k} / \mathrm{i}$ els aspirats $/ \mathrm{p}^{\mathrm{h}}, \mathrm{t}^{\mathrm{h}}$, $\mathrm{k}^{\mathrm{h}}$ / està en el moment en què la glotis tanca i es llança el so següent (un sonant, com ara una vocal). Com mostra la figura 2 adaptada de Wu (1992: 64), en emetre /p, t, k/, la glotis es tanca quasi en el mateix moment de la desclosió i s'emet immediatament el so següent; en cas de $/ \mathrm{p}^{\mathrm{h}}, \mathrm{t}^{\mathrm{h}}, \mathrm{k}^{\mathrm{h}} /$, la desclosió i el tancament de la glotis no es realitzen alhora, sinó que hi ha un interval entre els dos processos perquè una bafada surti per la boca.

Figura 2. Activitats glòtiques durant l'articulació dels oclusius sords

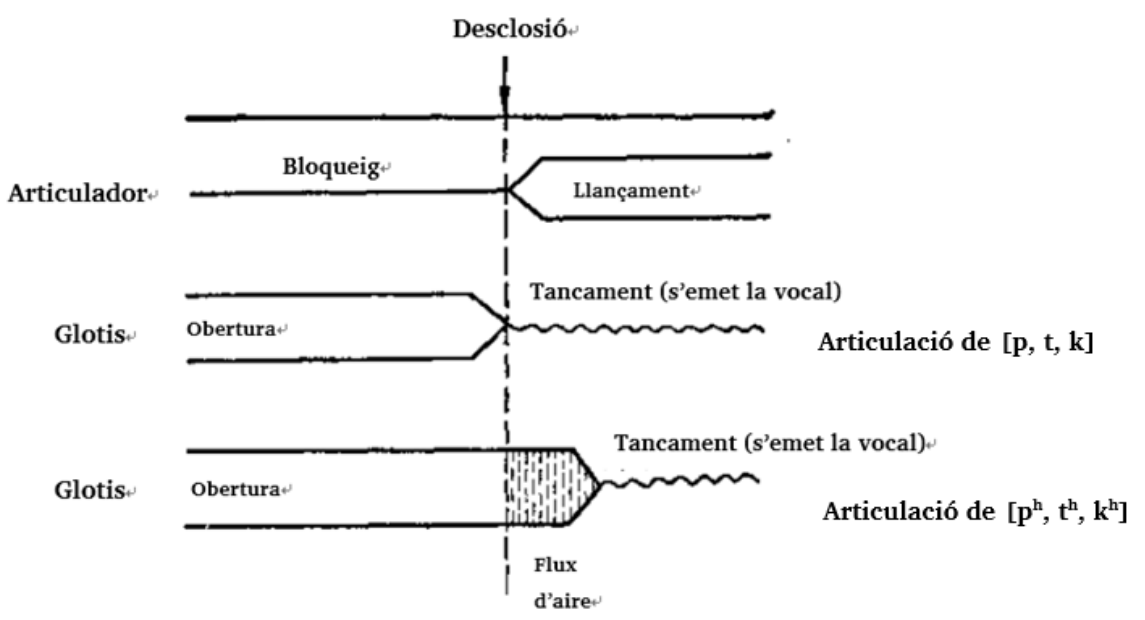

La diferència entre els sons sords i els sonors està en el moment en què els plecs glòtics comencen a vibrar. En articular els sords, aspirats o no aspirats, les activitats glòtiques comencen en el moment del tancament de la glotis i la vocalització del sonant, com indica la línia ondulada en la figura anterior. Al contrari, en emetre els sonors, les vibracions comencen abans de la desclosió. El temps que transcorre entre la desclosió i l'inici de les activitats glòtiques s'anomena moment d'engegada laríngia (MEL o Voice/Larynx Onset Time, VOT o LOT en anglès); per exemple, el MEL per a la síllaba [ka] és el temps entre el moment de separar el postdors lingual i la zona velar i l'inici de l'emissió de [a]. 
El MEL d'un oclusiu sord no aspirat és zero. Els sons $[p, t, k]$ del català i del castellà, i de l'anglès quan es troben en obertura "[s] + oclusiu", com ara en $S[\mathrm{p}]$ ain, $s[\mathrm{t}]$ op, $s[\mathrm{k}] \mathrm{y}$, tenen un MEL aproximadament igual a zero.

Un aspirat seguit d'un sonant té un MEL positiu. La intensitat de l'aspiració es relaciona directament amb la longitud del MEL: quant més gran és el MEL, més forta és l'aspiració.

El MEL d'un oclusiu sonor és negatiu i inferior a zero. En el cas d'un oclusiu completament sonor, les vibracions comencen al mateix moment que els òrgans articulatoris es posen en contacte. Si és un oclusiu parcialment sonor, com $[\mathrm{b}, \mathrm{d}, \mathrm{g}]$ a posició inicial en anglès (bad, $\boldsymbol{d a d}, \boldsymbol{g o d}$ ), la sonoritat comença en algun moment durant el bloqueig.

La taula següent mostra uns resultats de la producció del MEL dels oclusius de quatre llengües presentats per alguns estudiosos: xinès de Chen, Chao i Peng (2007), Liao (2005), Chao et al. (2006), Liu (2016); català de Julià i Muné (1981); castellà de Lisker i Abramson (1964), Banov (2014); anglès de Julià i Muné (1981), Lisker i Abramson (1964), Klatt (1975), citat per Chen, Chao i Peng (2007).

Taula 2. Amplitud de variació del MEL de quatre llengües

\begin{tabular}{|l|l|l|l|l|}
\hline Fonemes & Xinès & Català & Castellà & Anglès \\
\hline$/ \mathbf{b}, \mathbf{d}, \mathbf{g} /$ & & $\begin{array}{l}-156 /-48 \mathrm{~ms} \text { al principi de } \\
\text { frase, }-32 / 8 \mathrm{~ms} \text { a l'interior de } \\
\text { frase }\end{array}$ & $\leq-40 \mathrm{~ms}$ & $-150 / 40 \mathrm{~ms}$ \\
$/ \mathrm{p}, \mathbf{t}, \mathbf{k} /$ & $10 / 30 \mathrm{~ms}$ & $0 / 42 \mathrm{~ms}$ & $0 / 30 \mathrm{~ms}$ & $0 / 30 \mathrm{~ms}$ \\
$/ \mathbf{p}^{\mathrm{h}}, \mathbf{t}^{\mathrm{h}}, \mathbf{k}^{\mathrm{h}} /$ & $70 / 100 \mathrm{~ms}$ & & $30 / 100 \mathrm{~ms}$ \\
\hline
\end{tabular}

\subsection{Inventari d'oclusius del xinès}

En xinès hi ha tres parelles d'oclusius: /p- $\mathrm{p}^{\mathrm{h}} /, / \mathrm{t}-\mathrm{t}^{\mathrm{h}} / \mathrm{i} / \mathrm{k}-\mathrm{k}^{\mathrm{h}} /$, representats pels símbols $\left.<\mathrm{b}-\mathrm{p}\right\rangle$, $<\mathrm{d}-\mathrm{t}>\mathrm{i}<\mathrm{g}-\mathrm{k}>$ en pinyin, respectivament. Tot seguit es presenten uns exemples de paraules del xinès amb oclusius en l'obertura ${ }^{6}$.

[p-p $\mathbf{p}^{\mathrm{h}}$ ]: bilabials sords no aspirat/aspirat

$$
\begin{aligned}
\text { Ex.: } & \text { 爸 }<\text { ba }>\text { [pa] 'pare' } & \text { 冰 }<\text { bing }>\text { [pin] 'gel' } \\
& \text { 怕 }<\mathbf{p a}>\left[\mathbf{p}^{\mathrm{h}} \text { a }\right] \text { 'témer' } & \text { 瓶 }<\text { ping }>\left[\mathbf{p}^{\mathrm{h}}\right. \text { in] 'ampolla' }
\end{aligned}
$$

$\left[\mathbf{t}-\mathbf{t}^{\mathrm{h}}\right]$ : dentals (dentoalveolars) sords no aspirat/aspirat

$$
\begin{array}{lll}
\text { Ex.: } & \text { 弟 }<\mathbf{d i}>\text { ['ti] 'germà petit' } & \text { 蛋 }<\mathbf{d a n}>\text { ['tan] 'ou' } \\
& \text { 替 }<\mathbf{t i}>\left[\text { 't }^{\mathrm{h}} \mathbf{i}\right. \text { ] 'substituir' } & \text { 碳 }<\mathbf{t a n}>\text { ['t't }{ }^{\mathrm{h}} \text { an] 'carbó' }
\end{array}
$$

$\left[\mathbf{k}-\mathbf{k}^{\mathbf{h}}\right]$ : velars sords no aspirat/aspirat

$$
\begin{aligned}
& \text { Ex.: 哥 }<\mathbf{g e}>\text { ['kr] 'germà gran' 姑 }<\mathbf{g u}>\text { ['ku] 'tia (germana paterna)' } \\
& \text { 棵 }<\mathbf{k e}>\text { [' } \mathbf{k}^{\mathbf{h}} \boldsymbol{\gamma} \text { ] 'classificador d'arbres' 哭 }<\mathbf{k u}>\text { [' } \mathbf{k}^{\mathbf{h}} \mathbf{u} \text { ] 'plorar' }
\end{aligned}
$$

El xinès no té sistemàticament oclusius sonors. Tot $\mathrm{i}$ això, cal esmentar que en xinès els tres no aspirats /p, $\mathrm{t}, \mathrm{k} /$ poden ser sonoritzats en sílllabes àtones ( $\mathrm{amb}$ to neutre mitjà, per exemple) en posicions no inicials o intervocàliques en la parla contínua (Duanmu ${ }^{2} 2007 / 2000$ : $\$ 13.2$, Lin 2007: \$7.3), com ara/p/ [b] en 爸爸 <baba>/pa.pa/ ['pa.ba] 'pare'; /t/ [d] en 弟 弟 < didi> /ti.ti/ ['ti.di] 'germà petit';/k/ [g] en 哥哥 <gege > /kr.kr/ ['kr.gə] 'germà gran', entre altres. Duanmu i Lin també inclouen casos que un oclusiu sord s'afebleix a aproximant

6 Entre claus angulars hi ha les representacions del pinyin destonalitzades; les transcripcions fonètiques segons l'AFI van entre claudàtors i els significats de les paraules xineses, entre cometes simples. 
i donen els següents exemples, 哥哥 <gege> /kr.kr/ ['kr.yə] 'germà gran', 刚刚去 < ganggang $q u>\left[k \tilde{a} . \gamma \tilde{a}\right.$ ' $\left.t 6^{h w} y\right]$ 'acabar d'anar-hi'. Aquest fenomen de sonorització és pronunciació opcional que varia entre persones, $\mathrm{i}$ es presenta normalment en discurs ràpid i poc curat sense que el parlant se n'adoni; no forma part, per tant, de l'inventari d'oclusius estàndard del xinès.

\subsection{Inventari d'oclusius del català}

El català compta amb tres parelles d'oclusius: /p-b/, /t-d/ i /k-g/.

Taula 3. Els sons oclusius del català

\begin{tabular}{|l|l|l|l|}
\hline Mode d'articulació & Bilabial & Dental & Velar \\
\hline Oclusius & $/ \mathrm{p} / \mathrm{p}, / \mathrm{b} / \mathrm{b}$ & $/ \mathrm{t} / \mathrm{t}, / \mathrm{d} / \mathrm{d}$ & $/ \mathrm{k} / \mathrm{k}, \mathrm{g} / \mathrm{g}$ \\
Aproximants & $/ \mathrm{b} / \beta$ & $/ \mathrm{d} / \partial$ & $/ \mathrm{g} / \mathrm{\gamma}$ \\
\hline
\end{tabular}

Els tres sords $[\mathrm{p}, \mathrm{t}, \mathrm{k}]$ del català són equiparables als corresponents del xinès. Generalment no hi ha aspiració perceptible, llevat que els pronuncien amb èmfasi.

Els tres sonors $[b, d, g]$, junt amb els seus al-lòfons, els aproximants $[\beta, \gamma, \gamma]$, són propis del català i no existeixen en xinès.

\subsection{Estructura sil-làbica del xinès i distribució dels oclusius en la síl·laba}

L'estructura sil-làbica del xinès es pot representar amb el model $\mathrm{C}_{0-1} \mathrm{VC}_{0-1}$ (semivocal, nasal dental o velar) ( $\mathrm{V}=$ vocal; $\mathrm{C}=$ consonant o semivocal). El nucli és obligatori, mentre que l'obertura i la coda són opcionals. L'obertura, si existeix, pot ser formada per una sola consonant, una semivocal o una consonant amb característiques de semivocals $\mathrm{C}^{\mathrm{S}}\left(\mathrm{S}=\right.$ semivocal), ${ }^{7} \mathrm{i}$ teòricament tots els sons consonàntics del xinès excepte el nasal velar $[\mathrm{n}]$ poden aparèixer en l'obertura; la rima VC pot ser un diftong decreixent ([ej], [aj], [aw] o [ow]) o una combinació d'una vocal i un nasal dental o velar $([n, n])$.

S'illlustra el model de l'estructura sil-làbica del xinès amb la figura següent, i s'hi afegeixen exemples per a totes les possibles estructures fonotàctiques.

Figura 3. Estructura sil.làbica del xinès

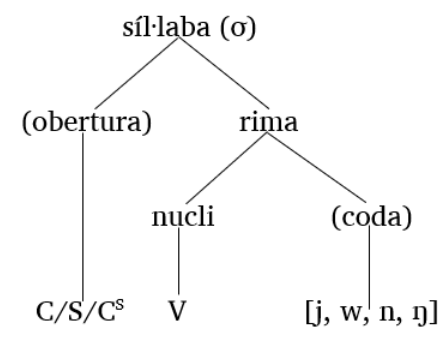

\footnotetext{
7 En xinès la semivocal que apareix entre la consonant de l'obertura i la vocal del nucli és més curta que els altres sons de la mateixa síl-laba, i pot canviar les característiques de la consonant precedent. Per exemple, en el mot xinès 岁 <sui> ['swej] 'edat', el so [s] s'articula amb arrodoniment dels llavis i la vocal [e] s'emet immediatament després de [s]; la semivocal [w] no té un interval perceptible com en el mot anglès sway [swer] 'balanceig, vaivé' (Chao 2002: 763-764, que ha donat la transcripció [sei] per al mot xinès i [swei] per al mot anglès). Alguns estudiosos de la fonologia xinesa consideren que la semivocal a l'interior de síl.laba forma un sol so amb la consonant precedent i proposen la forma de representació de " $\mathrm{C}^{G}$ ” $(\mathrm{G}=$ glide). Vegeu Duanmu 2007/2000: \$4.3, Lin 2007: \$5. Considerant aquesta peculiaritat del xinès, en el present treball no es considera la combinació de $\mathrm{C}^{\mathrm{S}}$ una obertura complexa, i s'utilitza $j, w, y$ amb superíndex per transcriure les paraules xineses amb semivocals a l'interior de sílllaba.
} 
Taula 4. Les possibles estructures fonotàctiques del xinès

\begin{tabular}{|c|c|}
\hline $\mathrm{V}$ & 我鸟 $<\mathrm{e}>$ ['r] 'oca (ocell)' \\
\hline $\mathrm{CV}$ & 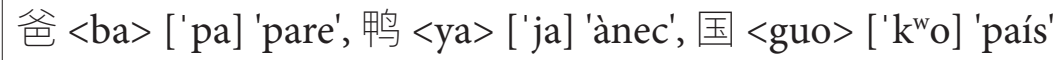 \\
\hline VC & 安 <an> ['an] 'pau', 赢 <ying> ['in] 'guanyar (la competició)', \\
\hline & 爱 $<$ ai $>$ ['aj] 'estimar', 呕 $<$ ou $>$ ['ow] 'vomitar' \\
\hline & 改 < gai > ['kaj] 'corregir', 考 <kao> ['k $\left.{ }^{\mathrm{h}} \mathrm{aw}\right]$ 'examinar', \\
\hline CVC & 咬 <yao> ['jaw] 'mossegar', 外 <wai> ['waj] 'exterior', \\
\hline & 三<san $>$ ['san] 'tres', 胖 $<$ pang $>$ ['p $\left.\mathrm{p}^{\mathrm{h}} \mathrm{an}\right]$ 'gras, grassa', \\
\hline & 远 <yuan> ['yen] 'lluny', 羊 <yang> ['jan] 'cabra, ovella' \\
\hline
\end{tabular}

\subsection{Estructura sil·làbica del català i distribució dels oclusius en la síl·laba}

L'estructura sil-làbica del català és del model $\mathrm{C}_{0-2} \mathrm{VC}_{0-3}$. El nucli és obligatori, però l'obertura i la coda són opcionals. L'obertura, si existeix, pot ser formada o bé per una consonant o una semivocal (obertura simple), o bé per dos segments (obertura complexa); la coda pot constar d'un màxim de dos segments si es troba enmig d'una paraula i d'un màxim de tres segments si es troba a final d'un mot. S'illustra l'estructura sil-làbica del català central amb la figura següent i es presenten totes les possibles estructures fonotàctiques del català central amb exemples (veg., entre altres, Lloret $\left({ }^{4} 2008 / 2002\right.$, \$5.1), Julià-Muné $\left.(2005, \$ 6.2)\right)$.

Figura 4. Estructura sil-làbica del català central

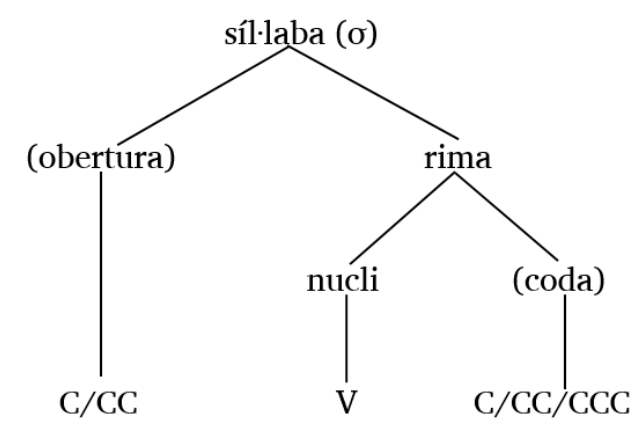

Taula 5. Les possibles estructures fonotàctiques del català central

\begin{tabular}{|l|l|}
\hline V & he [e], i [i], nua [ə] \\
CV & pa ['pa], iaia ['ja.jə] \\
VC & un [un], aigua ['aj] \\
CCV & clar ['kla], quatre ['kwa.trə], aigua [gwə] \\
CVC & nau ['naw], mal ['mal], raig ['ratf], portal [pur' tał] \\
VCC & arc ['ark], ulls ['u $\left.\Lambda \int\right]$ \\
VCCC & arcs ['arks], diürns ['urns] \\
CVCC & carn ['karn], porc ['pork] \\
CCVC & bloc ['błək], frau ['fraw] \\
CVCCC & serps ['serps], porcs ['porks] \\
CCVCC & blocs ['błəks], blancs ['błans] \\
CCVCCC & bruscs ['brusks], frescs ['fresks] \\
\hline
\end{tabular}




\subsection{Canvi segmental i resil-labificació en la parla contínua}

En xinès hi ha un límit clar i perceptible entre dues sílllabes adjacents; generalment no s'hi aplica resil-labificació $i$, per tant, una síllaba sense obertura no adquireix la consonant a la coda de la sílllaba precedent. Per exemple, la pronunciació de la paraula xinesa 天安门<Tianan Mén $>$ 'Porta de Tiananmèn' és [ $t^{\mathrm{hj}} æ n$.am 'mən] en lloc de ${ }^{\star}\left[\mathrm{t}^{\mathrm{hj}} æ . n a m\right.$ 'mən]. Els pocs casos de resil.labificació de síl.labes en contacte són d'expressions amb el marcador d'interjecció amb to feble 阿 <a> [a] (Duanmu 22007/2000: \$4.2, Lin 2007: \$5.2.4), sense implicacions d'oclusius, per exemple:

(1) Geminació de nasals o semivocals a coda:

$<$ tiān a $>$ ['thjæn] + [a]: ['thjæn.na] 'Déu meu!'

$<$ máng a $>$ ['man] + [a]: ['man.na] 'Ocupat!'

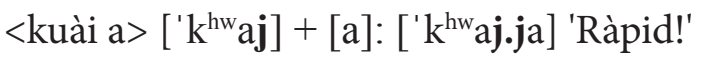

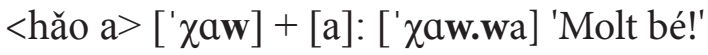

(2) Inserció de $[\mathrm{j} / \mathrm{w}]$ a l'obertura quan la síl.laba precedent acaba amb una vocal mitjana o alta:

$<$ bié a $>$ ['p $\left.{ }^{\mathrm{j} e}\right]+[\mathrm{a}]:$ ['p $\mathrm{j}$.ja] 'No, si us plau!'

$<$ wǒ a $>$ ['wo] + [a]: ['wo.ja] 'Jo!'

$<$ dú a $>$ ['tu] + [a]: ['tu.wa]/['tu.ja] 'Llegeix!'

En canvi, en la parla contínua del català un oclusiu que apareix a la coda pot ser assimilat, de sonoritat o de lloc o manera d'articulació, a la consonant inicial de la síl-laba següent, o ser redistribuït a la sílllaba següent. Per exemple:

(1) Assimilació de sonoritat:

$p o[\mathbf{t}]+[\mathrm{d}] \operatorname{ir}: p o[\mathbf{d} . \mathrm{d}] i r$

(2) Assimilació de lloc d'articulació:

$$
\text { po }[\mathbf{t}]+[\mathrm{k}] \text { alent: po }[\mathbf{k} . \mathrm{k}] \text { alent }
$$

(3) Assimilació de mode d'articulació:

vesti $[\mathbf{t}]+[\mathrm{m}]$ arró: vesti $[\mathbf{m} . \mathrm{m}]$ arró

(4) Resil-labificació

a) Sil-labificació de mots aillats:

pot ['pot], acabar [ə.kə' $\beta \mathrm{a}$ ]

b) Resil-labificació:

pot acabar [,po.tə.kə' $\beta \mathrm{a}]$

(5) Formació d'africats:

a) Sil-labificació de mots aillats: pot ['pot], ser ['se]

b) Resil-labificació:

pot ser [po'tse]

a) Sil-labificació de mots aillats: pot ['pot], jugar [zu'ya]

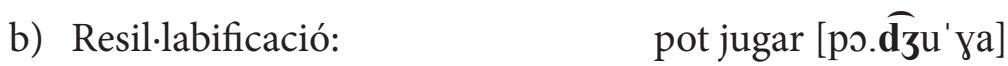

\subsection{Previsió de les dificultats i problemes de pronunciació del català per part d'estudiants sinòfons}

En aquest apartat s'analitzen les diferències d'inventari i de distribució dels oclusius entre el català i el xinès basant-se en la metodologia d'anàlisi contrastiva. Segons les diferències trobades i la noció de transferència, es preveuen els possibles problemes de pronunciació que poden presentar els aprenents sinòfons a l'hora d'aprendre el català. Es classifiquen els problemes previstos en diferents prioritats: prioritat alta, prioritat baixa $\mathrm{o}$ atenció esporàdica (Kenworthy 1987, Julià-Muné 2005). 


\section{Contrast d'inventari}

El tret distintiu de sonoritat dels oclusius és propi del català. Per això, els aprenents xinesos poden tenir problemes per distingir els oclusius sords i els sonors. Poden ensordir els sons $[b$, $\mathrm{d}, \mathrm{g}] \mathrm{i}[\beta, \gamma, \gamma]$ substituint-los per $[\mathrm{p}, \mathrm{t}, \mathrm{k}]$, respectivament. Els aproximants aspirants $[\beta, \gamma, \gamma]$ també poden ser substituïts per $[b, d, g]$.

\section{Possible efecte de transferència i gradació estratègica}

Prioritat alta: Confusió entre els oclusius sords i els sonors en l'obertura:

$/ \mathrm{p}-\mathrm{b} /[\mathrm{p}]-[\mathrm{b}, \beta]>$ xinès $[\mathrm{p}]($ pala $=$ bala, plau = blau, apropar $=$ aprovar $)$

$/ \mathrm{t}-\mathrm{d} /[\mathrm{t}]-[\mathrm{d}$, ð] $>$ xinès $[\mathrm{t}]($ tot $=\boldsymbol{d o t}$, teu $=$ Déu, cita $=\operatorname{SID} A)$

$/ \mathrm{k}-\mathrm{g} /[\mathrm{k}]-[\mathrm{g}, \mathrm{\gamma}]>$ xinès $[\mathrm{k}](\cos =$ gos, classe $=$ glaça, vaca $=$ vaga $)$

Prioritat baixa: Manca d'aproximantització de $[\beta, \gamma, \gamma]$ en l'obertura:

$$
\text { apro }[\beta] \text { ar }>\text { xinès }{ }^{*} \text { apro }[\mathrm{b}] \text { ar, } e[ð] a t>\text { xinès }{ }^{*} e[\mathrm{~d}] a t, v a[\gamma] a>\text { xinès }{ }^{*} v a[\mathrm{~g}] a
$$

El tret distintiu d'aspiració del xinès pot causar l'aspiració de $[\mathrm{p}, \mathrm{t}, \mathrm{k}]$ del català, especialment quan es troben a la coda.

Prioritat baixa: Aspiració de $[\mathrm{p}, \mathrm{t}, \mathrm{k}]$ a coda:

$$
c a[\mathrm{p}]>\text { xinès }{ }^{\star} c a\left[\mathrm{p}^{\mathrm{h}}\right], g a[\mathrm{t}]>\text { xinès }{ }^{*} g a\left[\mathrm{t}^{\mathrm{h}}\right], c u[\mathrm{k}]>\text { xinès }{ }^{*} c u\left[\mathrm{k}^{\mathrm{h}}\right]
$$

\section{Contrast de distribució sil.làbica}

És obvi que l'estructura sil-làbica del català és més complexa que la del xinès i les possibles estructures fonotàctiques del català són molt més nombroses. Aquesta diferència entre les dues llengües pot causar diversos obstacles que afecten la pronunciació del català per part dels aprenents sinòfons.

Com es descriu en $\$ 2.4$ i $\$ 2.5$, els oclusius del xinès només es presenten a l'obertura, mentre que en català es poden trobar tant a l'obertura com a la coda. A més, en xinès les obertures sil.làbiques són totes simples, però en català poden ser simples o complexes. Tenint en compte totes aquestes distincions, es preveuen els següents errors de pronunciació:

\section{Obertures simples}

Primer, ensordiment d'oclusius sonors, de prioritat alta, i manca d'aproximantització de prioritat baixa. Per a aquests problemes es proposa els mateixos exemples facilitats en la part de contrast d'inventari.

Segon, tenint en compte la possible sonorització idiosincràtica de /p, t, k/ del xinès en síllabes àtones en posicions no inicials o intervocàliques (\$2.2), es preveu el següent problema:

Prioritat alta: Sonorització de $[\mathrm{p}, \mathrm{t}, \mathrm{k}]$ en posicions intervocàliques àtones.

$$
\begin{aligned}
& c a[\mathrm{p}] a>\text { xinès }{ }^{*} c a[\mathrm{~b}] a, c a m[\mathrm{p}] u s>\text { xinès }{ }^{*} c a m[\mathrm{~b}] u s \\
& p o[\mathrm{t}] a>\text { xinès }{ }^{\star} p o[\mathrm{~d}] a, \operatorname{len}[\mathrm{t}] a>\text { xinès }{ }^{\star} \operatorname{len}[\mathrm{d}] a \\
& b o[\mathrm{k}] a>\text { xinès }{ }^{\star} b o[\mathrm{~g}] a, \operatorname{man}[\mathrm{k}] a>\text { xinès }{ }^{\star} \operatorname{man}[\mathrm{g}] a
\end{aligned}
$$

\section{Obertures complexes}

Dins les obertures complexes de l'estructura "oclusiu $+[1 / \mathrm{f}]$ " poden afegir una vocal curta o de durada normal, majoritàriament la vocal neutra [ə], per tal que sigui més fàcil d'articular. És possible que l'afegitó de vocal canviï la sil-labificació de la paraula catalana.

Prioritat baixa o alta: Afegiment de vocal addicional curta (PB) o normal (PA) dins obertures 
complexes "oclusiu $+[\mathrm{r} / \mathrm{l}]$ " amb possible canvi de sil-labificació: ${ }^{8}$

$[\mathrm{p}]$ rou $>$ xinès ${ }^{*}\left[\mathrm{p}^{\curvearrowright}\right]$ rou $\sim{ }^{*}[\mathrm{p} ə]$ rou,$[\mathrm{b}]$ lat $>$ xinès ${ }^{*}\left[\mathrm{~b}^{\curvearrowright}\right]$ lat $\sim{ }^{*}[\mathrm{~b} ə]$ lat

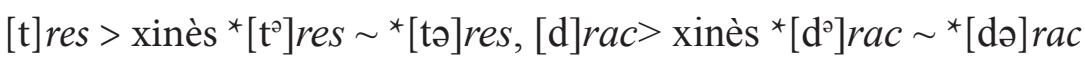

$[\mathrm{g}]$ roc $>$ xinès ${ }^{\star}\left[\mathrm{g}^{\ominus}\right]$ roc $\sim{ }^{\star}[\mathrm{g} ə] \mathrm{roc},[\mathrm{k}]$ lasse $>$ xinès ${ }^{\star}\left[\mathrm{k}^{\curvearrowright}\right]$ lasse $\sim{ }^{\star}[\mathrm{kə}]$ lasse

Codes simples o complexes

Els oclusius que apareixen a la coda, simple o complexa, poden ser modificats de diferents maneres. Poden ocórrer dues situacions contràries: afegitó de vocal després d'oclusius com el que passa a les obertures complexes, o escurçament, fins i tot elisió, dels sons consonàntics.

Prioritat baixa o alta: Afegiment de vocal curta (PB) o normal (PA) després d'oclusius a la coda amb possible C $C d S$.

$$
\begin{aligned}
& c a[\mathrm{p}]>\text { xinès }{ }^{*} c a\left[\mathrm{p}^{\curvearrowright}\right], \operatorname{pra}[\mathrm{t}]>\text { xinès }{ }^{*} \operatorname{pra}\left[\mathrm{t}^{\mathrm{t}}\right], \operatorname{dra}[\mathrm{k}]>\text { xinès }{ }^{*} d r a\left[\mathrm{k}^{\curvearrowright}\right] \\
& \text { si }[\mathrm{g}] n e \sim \operatorname{si}[\mathrm{g}] n e>\text { xinès }{ }^{\star} \text { si }\left[\mathrm{g}^{\curvearrowright}\right] \text { ne } \sim \operatorname{si}[\mathrm{g} \text { ə] }] \text { e } \\
& n a[\mathrm{ps}]>\text { xinès }{ }^{\star} n a\left[\mathrm{p}^{\curvearrowright} \mathrm{s}\right], c u[\mathrm{cs}]>\text { xinès }{ }^{*} c u\left[\mathrm{k}^{\curvearrowright} \mathrm{s}\right]
\end{aligned}
$$

Prioritat alta o baixa: Escurçament (PB) o elisió (PA) dels oclusius a la coda amb possible CdS:

$$
\begin{aligned}
& \text { car }=\text { carp, par }=\text { part, cor }=\text { corc }(\text { Julià-Muné 2011) }
\end{aligned}
$$

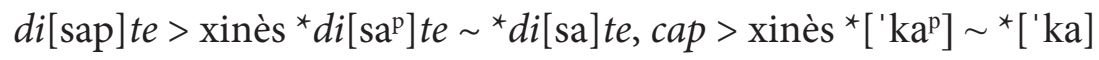

$$
\begin{aligned}
& \text { prat }>\text { xinès }{ }^{*}\left[\text { 'prat }^{\mathrm{t}}\right] \sim{ }^{*}[\text { 'pra] }], a[\mathrm{~d} \text {.d }] \text { icció }>\text { xinès }{ }^{\star} a[\mathrm{~d}] \text { icció } \sim^{*} a[\text { ð] }] \text { icció } \\
& \text { drac }>\text { xinès }{ }^{*}\left[{ }^{\prime} \mathrm{dra} \mathrm{a}^{\mathrm{k}}\right] \sim{ }^{*}[\text { 'dra }],[\mathrm{uk}] \text { tubre }>\text { xinès }{ }^{\star}\left[\mathrm{u}^{\mathrm{k}}\right] \text { tubre } \sim{ }^{*}[\mathrm{u}] \text { tubre } \\
& e[\text { g.z }] \text { amen }>\text { xinès }{ }^{*} e\left[{ }^{g} . z\right] \text { amen } \sim{ }^{*} e[z] \text { amen }
\end{aligned}
$$

Finalment, els fenòmens de contacte i resil-labificació esmentats en $\$ 2.6$ poden ser desconeguts pels xinesos. Llavors, es preveu la no realització de l'assimilació de sonoritat, de lloc o mode d'articulació, formació d'africats i resil-labificació (PA).

$$
\begin{array}{ll}
\text { pot dir }>\text { xinès }{ }^{*} \text { po }[\mathbf{t} \mid \mathrm{d}] \text { ir, } & \text { pot calent }>\text { xinès }{ }^{*} \text { po }[\mathbf{t} \mid \mathrm{k}] \text { alent } \\
\text { vestit marró }>\text { xinès }{ }^{*} \text { vesti }[\mathbf{t} \mid \mathrm{m}] \text { arró, }, & \text { pot acabar }>\text { xinès }{ }^{*} \text { po }[\mathbf{t} \mid \text { ə] }] \text { cabar } \\
\text { pot ser }>\text { xinès }{ }^{*} \text { po }[\mathbf{t} \mid \mathrm{s}] \text { er, } & \text { pot jugar }>\text { xinès }{ }^{*} \text { pot }[\mathbf{t} \mid 3] \text { ugar }
\end{array}
$$

\section{Part pràctica}

\subsection{El corpus i els informants}

\section{El corpus}

Per poder recollir tots els tipus d'errors o imprecisions de pronunciació relacionats amb els oclusius del català, es va dissenyar un corpus de 115 mots o compostos que comprenen tots els sons oclusius en totes les posicions possibles (obertura simple o complexa a l'inici o l'interior de mot, coda simple o complexa a l'interior o al final de mot). Per exemple: parells mínims pot-vot amb [p-b] en obertura inicial simple i plau-blau amb [p-b] en obertura inicial complexa; xampú i futbol amb [p, b] en obertura interna simple, Eixample i la Rambla amb $[\mathrm{p}, \mathrm{b}]$ en obertura interna complexa; novembre i Bíblia amb $[\beta]$ en obertura interna simple o complexa, dissabte amb /b/ [p] a coda interna simple, obscur amb /b/ [p] a coda interna complexa, cap amb [p] a coda final simple i, naps amb [p] a coda final complexa.

8 D'ara en davant s'utilitza l'abreviatura $C d S$ per referir-se a canvi de sil-labificació. 


\section{L'enquesta}

L'enquesta està formada per dos exercicis: un d'elocució de paraules realitzada amb una presentació d'imatges o preguntes, i l'altre de lectura en veu alta de paraules que no poden ser representades per imatges o no són familiars per als informants xinesos (Casp, troca, desdir, pot dir...). En la part d'elocució de paraules, s'hi presentava imatges perquè els informants les identifiquessin (com ara finestra, cavalls, xampú, futbol...), unes preguntes perquè contestessin (com ara Quins són els dies de la setmana?), números o paraules en xinès perquè diguessin les paraules en català corresponents (13, explicar, advocat...). Si els informants no sabien la resposta, es visualitzava la paraula enquestada perquè la llegissin en veu alta. Les respostes van ser enregistrades amb una gravadora digital (AIGO R6601) amb freqüència de mostra de $48 \mathrm{KHz}$.

\section{Els informants}

Tot i que no era gaire gran la població xinesa que podia parlar el català, es va intentar localitzar informants de tots nivells tenint en compte les característiques de diferents grups de xinesos: immigrants que tenien negocis (restaurant, bar, basar...); estudiants universitaris, i els fills d'immigrants. Formaven part del primer grup majoritàriament gent originària de Qingtian i Wenzhou, que tenia un nivell d'educació comparativament més baix. Aquesta població, com que no tenia suficients coneixements tant de llengües estrangeres (català, anglès i espanyol) com de xinès estàndard, perquè solien parlar altres varietats del xinès com a L1, era irrellevant per a la finalitat d'aquest estudi. El segon grup, que corresponia als estudiants xinesos, comprenia dos subgrups: un d'alumnes que no parlaven ni castellà ni català, que feien programes en anglès (per exemple, els doctorands becats pel govern xinès) i que, per això, no complien els requisits de l'estudi; l'altre d'estudiants que van estudiar anglès (a la Xina) i espanyol (a la Xina o aquí en les escoles d'idiomes) abans de començar a estudiar a les universitats catalanes. Aquestes persones eren les més representatives dels aprenents de català i els que s'adeien més amb les característiques d'aquest estudi. Pertanyien al tercer grup els fills d'immigrants que es van escolaritzar aquí i que havien entrat a la universitat. La majoria d'aquests es podien comunicar fluidament en castellà i català. Aquestes persones, com que parlaven xinès abans d'emigrar de la Xina $i$, si més no, es comunicaven amb els seus familiars en aquesta llengua a la vida quotidiana, podien presentar errors o accents estrangers a l'hora de parlar català. Per això, eren possibles informants per a l'estudi.

Es va gravar la pronunciació de 23 estudiants universitaris xinesos (17 dones i 6 homes) de la UB i la UAB de 18-33 anys que vivien a l'àrea metropolitana de Barcelona en el moment de l'entrevista. Després se'n van descartar 4 perquè presentaven problemes personals poc representatius: vocalització no clara amb balbuceig (2), nivell baix i pronunciació poc natural per timidesa (1) i massa transferència de l'anglès (1). Al final es van seleccionar 19 informants.

Els de número 1-10, incloent una doctoranda de Taiwan, eren de la carrera d'estudis hispànics i havien vingut a Catalunya per cursar estudis de màster o doctorat; parlaven, per tant, el xinès com a llengua materna (L1), l'anglès i l'espanyol com a L2 i L3, i el català i altres llengües com a L4/L5, etc. Havien participat en els cursos d'introducció a la llengua catalana a la universitat; per tant, es considerava que tenien nivell inicial-bàsic del català. Els de número 11-15, també estudiants de màster o doctorat, tenien un nivell entre B1 i B2 del català; havien fet més cursos del català (les informants 11 i 13), havia llegit sovint en aquesta llengua per estudis doctorals (el 14), o tenien més relació social amb catalans (amics, xicots) i així havien tingut més contacte amb el català (els 12 i 15). Finalment, els informants 16-19 eren fills d'immigrants que es van escolaritzar a Barcelona; entre ells, una era nascuda a Catalunya (la 19) mentre que els altres tres van venir després d'acabar l'escola primària a la Xina (els 16-18). Tenien un nivell comparativament més alt del català que els informants 1-15. 


\subsection{Resultats $i$ anàlisi d'errors}

Transcrivint i analitzant les pronúncies enregistrades amb l'ajuda del programa Praat, es va obtenir un corpus de pronúncies diverses, el qual, per un costat, permetia fer una valoració quantitativa dels problemes de pronunciació que tenien els aprenents xinesos, i, per l'altre, podia sustentar els estudis d'estratègies didàctiques per millorar la pronunciació.

Els informants van presentar diversos tipus d'errors de pronunciació. Es pot comprovar que els problemes previstos a partir d'anàlisi contrastiva són precisos. Concretament, s'ha comprovat els següents casos d'interferència de l'L1 que es poden classificar en dos aspectes: el segmental i el suprasegmental sillàbic.

\subsubsection{Aspecte segmental}

Primer, els informants, especialment els que tenien nivell inicial-bàsic del català, van presentar freqüentment la no distinció de sonoritat i la confusió entre els oclusius sords i els sonors. D'una banda, van substituir els oclusius sonors /b, d, g/ pels sons sords corresponents i els aproximants $[\beta, \gamma, \gamma]$ per $[b, d, g]$, respectivament.

Taula 6. Resultats quantitatius d'ensordiment de /b, d, g/ (PA)

\begin{tabular}{|c|c|c|c|c|}
\hline Errors & Mots enquestats & $\begin{array}{l}\text { Nivell inicial-bàsic } \\
\text { (10) }\end{array}$ & Nivell mitjà (5) & Nivell alt (4) \\
\hline \multirow{8}{*}{$\begin{array}{l}/ b /:[b, \beta] \\
>[p]\end{array}$} & vot & $1 / 10$ & 0 & 0 \\
\hline & blat & $1 / 10$ & 0 & $1 / 4$ \\
\hline & brau & 0 & $1 / 5$ & $1 / 4$ \\
\hline & bicicleta & $2 / 10$ & 0 & $2 / 4$ \\
\hline & novembre & $1 / 10$ & 0 & 0 \\
\hline & Casa Batlló & $3 / 10$ & 0 & $1 / 4$ \\
\hline & cabells & $2 / 10$ & $1 / 5$ & 0 \\
\hline & arbre & 0 & 0 & $1 / 4$ \\
\hline \multirow{8}{*}{$\begin{array}{l}/ \mathrm{d} /:[\mathrm{d}, \partial] \\
>[\mathrm{t}]\end{array}$} & dos & $1 / 10$ & 0 & 0 \\
\hline & droga & $1 / 10$ & $1 / 5$ & $1 / 4$ \\
\hline & desdir & $2 / 10$ & $1 / 5$ & 0 \\
\hline & divendres & $1 / 10$ & 0 & 0 \\
\hline & faldilla & $3 / 10$ & 0 & $1 / 4$ \\
\hline & quadre & $2 / 10$ & 0 & 0 \\
\hline & desdir & $4 / 10$ & $1 / 5$ & $2 / 4$ \\
\hline & set-cents dos & $1 / 10$ & 0 & 0 \\
\hline \multirow{8}{*}{$\begin{array}{l}/ \mathrm{g} /:[\mathrm{g}, \mathrm{\gamma}] \\
>[\mathrm{k}]\end{array}$} & gol & $2 / 10$ & $3 / 5$ & $1 / 4$ \\
\hline & gaspatxo & $4 / 10$ & $1 / 5$ & $1 / 4$ \\
\hline & congrés & $1 / 10$ & $1 / 5$ & 0 \\
\hline & triangle & $1 / 10$ & 0 & 0 \\
\hline & Afganistan & $1 / 10$ & 0 & 0 \\
\hline & set gegants & $3 / 10$ & 0 & 0 \\
\hline & sigla & $3 / 10$ & $1 / 5$ & $1 / 4$ \\
\hline & examen & $9 / 10$ & $2 / 5$ & $4 / 4$ \\
\hline
\end{tabular}


Taula 7. Resultats quantitatius de manca d'aproximantització de $[\beta, \gamma, \gamma](\mathrm{PB})$

\begin{tabular}{|l|l|l|l|l|}
\hline Errors & Mots enquestats & $\begin{array}{l}\text { Nivell inicial-bàsic } \\
(\mathbf{1 0})\end{array}$ & Nivell mitjà (5) & Nivell alt (4) \\
\hline \multirow{5}{*}[\beta]{$>[\mathrm{b}]$} & novembre & $1 / 10$ & 0 & $1 / 4$ \\
& aprovar & $2 / 10$ & $1 / 5$ & 0 \\
& alvocat & $4 / 10$ & 0 & $2 / 4$ \\
& Casa Batlló & $6 / 10$ & $5 / 5$ & $3 / 4$ \\
& febrer & $4 / 10$ & $2 / 5$ & $1 / 4$ \\
& cabra & $7 / 10$ & $2 / 5$ & $1 / 4$ \\
\hline \multirow{5}{*}[ð]{$>[\mathrm{d}]]$} & migdia & $10 / 10$ & $5 / 5$ & $4 / 4$ \\
& desdir & $6 / 10$ & $4 / 5$ & 0 \\
& set-cents dos & $9 / 10$ & $5 / 5$ & $4 / 4$ \\
& catedral & $9 / 10$ & $3 / 5$ & $3 / 4$ \\
& quadre & $8 / 10$ & $4 / 5$ & $3 / 4$ \\
\hline \multirow{5}{*}[\text{]}]{$>[\mathrm{g}]$} & agost & $6 / 10$ & $2 / 5$ & $2 / 4$ \\
& set gegants & $6 / 10$ & $4 / 5$ & $3 / 4$ \\
& droga & $5 / 10$ & $1 / 5$ & $1 / 4$ \\
& Afganistan & $8 / 10$ & $4 / 5$ & $2 / 4$ \\
& sigla & $4 / 10$ & $3 / 5$ & $1 / 4$ \\
& bolígraf & $7 / 10$ & $3 / 5$ & $2 / 4$ \\
& sagrada & $5 / 10$ & $4 / 5$ & 0 \\
\hline
\end{tabular}

També s'ha detectat casos d'escurçament dels aproximants:

Taula 8. Resultats quantitatius d'escurçament d'aproximants (PB)

\begin{tabular}{|l|l|l|l|l|}
\hline Errors & Mots enquestats & Nivell inicial-bàsic & Nivell mitjà & Nivell alt \\
\hline$\left.[\beta]>{ }^{\beta}\right]$ & $\begin{array}{l}\text { novembre } \\
\text { aprovar }\end{array}$ & 0 & $1 / 5$ & 0 \\
\hline$\left.[ð]>{ }^{\gamma}\right]$ & catedral & 0 & 0 & 0 \\
\hline \multirow{2}{*}[]{$\left.^{\gamma}>{ }^{\gamma}\right]$} & $\begin{array}{l}\text { agost } \\
\text { aigua }\end{array}$ & 0 & $1 / 5$ & 0 \\
\hline
\end{tabular}

De l'altra banda, els informants que havien dominat l'articulació dels oclusius sonors van presentar la ultracorrecció substituint $[\mathrm{p}, \mathrm{t}, \mathrm{k}]$ en posicions inicials o sílllabes tòniques pels no xinesos $[\mathrm{b}, \mathrm{d}, \mathrm{g}]$ o $[\beta, \gamma, \mathrm{\gamma}]$, respectivament. ${ }^{9}$ 
Taula 9. Resultats quantitatius d'ultracorrecció (PA)

\begin{tabular}{|l|l|l|l|l|}
\hline Errors & Mots enquestats & Nivell inicial-bàsic & Nivell mitjà & Nivell alt \\
\hline \multirow{5}{*}[\mathrm{p}]{$>[\mathrm{b}, \beta]$} & pot & $3 / 10$ & $2 / 5$ & 0 \\
& paper & $4 / 10$ & $1 / 5([\beta])$ & 0 \\
& xampú & $2 / 10$ & $1 / 5$ & 0 \\
& xampany & $6 / 10$ & 0 & 0 \\
\hline \multirow{5}{*}[\mathrm{t}]{$>[\mathrm{d}$, ð] $]$} & troca & $5 / 10$ & 0 & $1 / 4$ \\
& text & 0 & $1 / 5$ & 0 \\
& tenir & 0 & 0 & $1 / 4$ \\
& setembre & $1 / 10([ð])$ & 0 & 0 \\
\hline \multirow{5}{*}[\mathrm{k}]{$>[\mathrm{g}, \mathrm{\gamma}]$} & classe & $2 / 10$ & $1 / 5$ & 0 \\
& cavalls & $1 / 10$ & $1 / 5$ & 0 \\
& advocat & 0 & $3 / 5([\mathrm{~g}, \mathrm{\gamma}])$ & $2 / 4$ \\
& bicicleta & $4 / 10([\mathrm{~g}, \mathrm{\gamma}]$ & $1 / 5([\mathrm{~g}])$ & $1 / 4([\mathrm{~g}])$ \\
\hline
\end{tabular}

Aquest problema es pot explicar amb la teoria d'interllengua. Durant el procés d'aprenentatge, han de superar dues etapes abans de dominar totalment la pronunciació dels oclusius: la primera és la d'articulació amb l'objectiu de poder emetre correctament els sonors quan pronuncien paraules aïllades amb cura; la segona és la de distinció a fi de poder pronunciar precisament els sords i els sonors en tots contextos sense haver de recordar-se de la necessitat de distingir-los. En altres paraules, la segona etapa, en què es presenta la ultracorrecció, és un període de pronunciació esporàdica en què s'emeten els sords o els sonors depenent de l'atzar, el costum de cadascú o les característiques del discurs (ràpida o lenta, curada o descurada, formal o informal).

L'aspiració de [p, $\mathrm{t}, \mathrm{k}$ ], com a interferència del xinès, s'ha presentat en la pronunciació dels informants.

Taula 10. Resultats quantitatius de l'aspiració /p, t, k/ (PB)

\begin{tabular}{|l|l|l|l|l|}
\hline Errors & Mots enquestats & Nivell inicial-bàsic & Nivell mitjà & Nivell alt \\
\hline \multirow{5}{*}[\mathrm{p}]{$>\left[\mathrm{p}^{\mathrm{h}}\right]$} & xampú & $2 / 10$ & 0 & 0 \\
& prat & $1 / 10$ & 0 & 0 \\
& cap & 0 & 0 & $1 / 4$ \\
& naip & $1 / 10$ & $2 / 5$ & 0 \\
\hline \multirow{5}{*}[\mathrm{t}]{$>\left[\mathrm{t}^{\mathrm{h}}\right]$} & dit petit & $1 / 10$ & 0 & 0 \\
& texts & $3 / 10$ & 0 & 0 \\
& prat & $4 / 10$ & $4 / 5$ & $2 / 4$ \\
& fruit & $4 / 10$ & $2 / 5$ & $1 / 4$ \\
\hline \multirow{5}{*}[\mathrm{k}]{$>\left[\mathrm{k}^{\mathrm{h}}\right]$} & camp & $2 / 10$ & 0 & 0 \\
& drac & $1 / 10$ & $1 / 5$ & 0 \\
& txec & $5 / 10$ & 0 & $1 / 4$ \\
& porc & $2 / 10$ & $1 / 5$ & 0 \\
\hline
\end{tabular}


A més de la confusió d'oclusius sord-sonora i de l'aspiració, la interferència de [v] de l'anglès també ha presentat en la pronunciació dels informants.

Taula 11. Interferència de $[\mathrm{v}]$ per $\mathrm{a}<\mathrm{v}>/ \mathrm{b} /(\mathrm{PA})$

\begin{tabular}{|l|l|l|l|}
\hline Mots enquestats & Nivell inicial-bàsic (10) & Nivell mitjà (5) & Nivell alt (4) \\
\hline vot & $3 / 10$ & $2 / 5$ & 0 \\
novembre & $8 / 10$ & $2 / 5$ & 0 \\
alvocat & $5 / 10$ & $2 / 5$ & 0 \\
aprovar & $2 / 10$ & $2 / 5$ & 0 \\
\hline
\end{tabular}

\subsubsection{Aspecte suprasegmental sil-làbic}

La no distinció de sonoritat pels oclusius en xinès ha causat la sonorització d'oclusius sords en posicions àtones no inicials $(\$ 2.2)$.

Taula 12. Resultats quantitatius de sonorització d'oclusius sords en posicions àtones no inicials (PA)

\begin{tabular}{|l|l|l|l|l|}
\hline Errors & Mots enquestats & Nivell inicial-bàsic & Nivell mitjà & Nivell alt \\
\hline \multirow{5}{*}[\mathrm{p}]{$>[\mathrm{b}, \beta]$} & tapes & $1 / 10([\beta])$ & $2 / 5([\beta, \mathrm{b}])$ & 0 \\
& Eixample & $7 / 10$ & $2 / 5$ & $1 / 4$ \\
& aplaudir & $3 / 10([\beta, \mathrm{b}])$ & $2 / 5([\beta, \mathrm{b}])$ & 0 \\
& aprovar & $7 / 10([\beta, \mathrm{b}])$ & 0 & 0 \\
\hline \multirow{5}{*}[\mathrm{t}]{$>[\mathrm{d}, \mathrm{\delta}]$} & etcètera & $4 / 10([ð, \mathrm{~d}])$ & $1 / 5([ð])$ & 0 \\
& catedral & $3 / 10$ & 0 & $2 / 4$ \\
& pregunta & $2 / 10$ & $1 / 5$ & 0 \\
\hline \multirow{5}{*}[\mathrm{k}]{$>[\mathrm{g}, \mathrm{\gamma}]$} & cinquanta-quatre & $3 / 10$ & $1 / 5$ & 0 \\
& cercle & $1 / 10$ & 0 & 0 \\
& Àfrica & $2 / 10$ & 0 & 0 \\
& dimecres & $3 / 10([\gamma, \mathrm{g}])$ & $2 / 5([\gamma, \mathrm{g}])$ & $2 / 4([\mathrm{\gamma}, \mathrm{g}])$ \\
\hline
\end{tabular}

A causa de les distincions de l'estructura sil-làbica i la distribució dels oclusius en la síl-laba que hi ha entre les dues llengües, els informants van cometre diversos tipus d'errors amb possible CdS. Els oclusius dins obertures complexes del tipus "oclusiu + [1/r]" o en codes són problemàtics per als informants xinesos, ja que en xinès no es troben mai en aquelles posicions. La manca d'una vocal de suport darrere ha causat els següents tipus d'errors.

Primer, afegitó de vocals curtes ${ }^{10}$ o de durada normal amb possible $C d S$ :

10 De fet, a causa de la naturalitat física, en el sonograma de la pronunciació dels parlants nadius del català també es pot notar una vocal molt curta entre l'oclusiu i el líquid que normalment dura menys de 30 ms, així que no es percep per les orelles i no s'indica en les transcripcions. En canvi, la vocal afegida pels parlants xinesos dura més de $30 \mathrm{~ms}$ i a vegades és perceptible. Segons l'anàlisi sonogràfica del Praat, si les vocals afegides duren menys de $30 \mathrm{~ms}$, no s'indiquen en les transcripcions; si duren entre 30 i $50 \mathrm{~ms}$ (ambdós inclosos), es consideren vocals intrusives sense $C d S$; si són més llargues de 50 ms però més curtes que els altres sons al voltant, es consideren nuclis sil·làbics curts amb CdS (Butler, 2014). 
Taula 13. Resultats quantitatius d'afegitó de vocals després d'oclusius

\begin{tabular}{|c|c|c|c|c|}
\hline Errors & Mots enquestats & $\begin{array}{l}\text { Nivell inicial } \\
\text {-bàsic }\end{array}$ & Nivell mitjà & Nivell alt \\
\hline \multirow{9}{*}{$\begin{array}{l}\text { Nuclis }[\partial, \mathrm{u}] \text { curts dins ober- } \\
\text { tures/codes complexes amb } \\
\text { CdS (PA) }\end{array}$} & cabra & $1 / 10\left(\left[\mathrm{~b}^{\ominus}\right]\right)$ & $1 / 5\left(\left[\mathrm{~d}^{\ominus}\right]\right)$ & 0 \\
\hline & droga & $1 / 10\left(\left[\mathrm{~d}^{\mathrm{u}}\right]\right)$ & 0 & 0 \\
\hline & catedral & $1 / 10\left(\left[\mathrm{~d}^{\top}\right]\right)$ & 0 & 0 \\
\hline & croquetes & 0 & $1 / 5\left(\left[\mathrm{k}^{\curvearrowright}\right]\right)$ & 0 \\
\hline & concret & 0 & $1 / 5\left(\left[\mathrm{k}^{\curvearrowright}\right]\right)$ & 0 \\
\hline & cercle & 0 & $1 / 5\left(\left[\mathrm{k}^{\curvearrowright}\right]\right)$ & 0 \\
\hline & grassa & 0 & $1 / 5\left(\left[g^{\curvearrowright}\right]\right)$ & 0 \\
\hline & sigla & 0 & $1 / 5\left(\left[\mathrm{k}^{\curvearrowright}\right]\right)$ & 0 \\
\hline & llargs & $1 / 10\left(\left[\mathrm{~g}^{2} \mathrm{~s}\right]\right)$ & 0 & 0 \\
\hline \multirow{3}{*}{$\begin{array}{l}\text { Nucli [ə] de durada normal } \\
\text { dins obertures complexes } \\
\text { amb CdS (PA) }\end{array}$} & cercle & 0 & $1 / 5$ & 0 \\
\hline & glaça & $1 / 10$ & 0 & 0 \\
\hline & triangle & $1 / 10$ & $1 / 5$ & 0 \\
\hline \multirow{5}{*}{$\begin{array}{l}\text { Nuclis }[\vartheta, \mathrm{u}, \mathrm{i}] \text { de durada nor- } \\
\text { mal a codes amb CdS (PA) }\end{array}$} & calbs & $1 / 10$ ([bus]) & 0 & 0 \\
\hline & exempt & $1 / 10([\mathrm{t} ə])$ & 0 & 0 \\
\hline & Casps & $1 / 10$ ([bus]) & 0 & 0 \\
\hline & Casa Batlló & 0 & $1 / 5[\mathrm{ti}]$ & 0 \\
\hline & augment & $1 / 10([\mathrm{gu}])$ & $1 / 5([\mathrm{gu}])$ & 0 \\
\hline \multirow{12}{*}{$\begin{array}{l}\text { [ə] molt curta }(<50 \mathrm{~ms}) \text { sen- } \\
\text { se CdS }(\mathrm{PB})\end{array}$} & blat & $1 / 10$ & 0 & 0 \\
\hline & la Rambla & 0 & $1 / 5$ & 0 \\
\hline & troncs & $1 / 10$ & $1 / 5$ & 0 \\
\hline & drac & $1 / 10$ & 0 & 0 \\
\hline & catedral & $2 / 10$ & 0 & 0 \\
\hline & quadre & $1 / 10$ & 0 & 0 \\
\hline & bicicleta & $1 / 10$ & $1 / 5$ & 0 \\
\hline & concret & $1 / 10$ & 0 & $1 / 4$ \\
\hline & cercle & $1 / 10$ & 0 & 0 \\
\hline & grassa & $1 / 10$ & 0 & 0 \\
\hline & bolígraf & 0 & $1 / 5$ & 0 \\
\hline & & $1 / 10$ & & 0 \\
\hline
\end{tabular}


Segon, elisió dels oclusius a coda (PA):

Taula 14. Resultats quantitatius d'elisió d'oclusius a coda

\begin{tabular}{|l|l|l|l|}
\hline Mots enquestats & Nivell inicial-bàsic & Nivell mitjà & Nivell alt \\
\hline dissabte & $1 / 10$ & 0 & 0 \\
calb & $3 / 10$ & $2 / 5$ & $1 / 4$ \\
verb & $4 / 10$ & $1 / 5$ & 0 \\
verbs & $1 / 10$ & $1 / 5$ & 0 \\
naip & $4 / 10$ & 0 & $1 / 4$ \\
Casp & $1 / 10$ & 0 & 0 \\
fluid & 0 & $3 / 5$ & $1 / 4$ \\
addicció & $9 / 10$ & $5 / 5$ & $4 / 4$ \\
drac & 0 & 0 & $1 / 4$ \\
calc & $2 / 10$ & 0 & 0 \\
calcs & $2 / 10$ & $1 / 5$ & 0 \\
porc & 0 & $2 / 5$ & $1 / 4$ \\
mosaic & 0 & $1 / 5$ & 0 \\
rauc & $1 / 10$ & 0 & 0 \\
octubre & $1 / 10$ & 0 & 0 \\
addicció & $1 / 10$ & $1 / 5$ & $1 / 4$ \\
auxili & $6 / 10$ & $3 / 5$ & $4 / 4$ \\
llargs & 0 & $1 / 5$ & $1 / 4$ \\
text & $1 / 10(s t)$ & 0 & 0 \\
examen & 0 & $1 / 5$ & 0 \\
\hline
\end{tabular}

També s'ha detectat casos d'elisió de /g/ en obertura complexa <gu> [gw, $\mathrm{\gamma w}$ ] i, curiosament, els van presentar només els informants de nivell alt. És un tipus d'error que no s'ha previst en la part d'estudi contrastiu.

Taula 15. Resultats quantitatius de l'elisió de /g/ (PA)

\begin{tabular}{|l|l|l|l|}
\hline Mots enquestats & Nivell inicial-bàsic & Nivell mitjà & Nivell alt \\
\hline guants & 0 & 0 & $1 / 4$ \\
pingüí & 0 & 0 & $1 / 4$ \\
llengua & 0 & 0 & $1 / 4$ \\
aigüera & 0 & 0 & $2 / 4$ \\
Paraguai & 0 & 0 & $3 / 4$ \\
aigua & 0 & 0 & $1 / 4$ \\
\hline
\end{tabular}


Tercer, escurçament dels oclusius en obertures complexes o codes. Només van posar els òrgans articulatoris en contacte sense realitzar la desclosió.

Taula 16. Resultats quantitatius de l'escurçament d'oclusius (PB)

\begin{tabular}{|l|l|l|l|l|}
\hline Errors & Mots enquestats & Nivell inicial-bàsic & Nivell mitjà & Nivell alt \\
\hline \multirow{5}{*}[\mathrm{p}]{$\left.>{ }^{\mathrm{p}}\right]$} & cap & $1 / 10$ & 0 & 0 \\
& Casp & $2 / 10$ & 0 & 0 \\
\hline & verb & 0 & $1 / 5$ & $2 / 4$ \\
\hline & prat & 0 & $1 / 5$ & 0 \\
& vot & $1 / 10$ & 0 & 0 \\
$\left.[\mathrm{t}]>{ }^{\mathrm{t}}\right]$ & fruit & 0 & $1 / 5$ & 0 \\
& fluid & $1 / 10$ & 0 & 0 \\
& iogurt & $1 / 10$ & 0 & 0 \\
& agost & 0 & $1 / 5$ & 0 \\
\hline$\left.[\mathrm{d}]>{ }^{\mathrm{d}}\right]$ & droga & 0 & 0 & $1 / 4$ \\
\hline$\left.[\mathrm{k}]>{ }^{\mathrm{k}}\right]$ & txec & $1 / 10$ & 0 & 0 \\
& bosc & $1 / 10$ & 0 & 0 \\
\hline$\left.[\mathrm{g}]>{ }^{\mathrm{g}}\right]$ & augment & 0 & 0 & $1 / 4$ \\
\hline
\end{tabular}

Acabant de revisar els errors produïts als segments, passem a l'aspecte de fenòmens de contacte $(\$ 2.6, \$ 2.7)$. S'ha comprovat que els informants, en la majoria dels casos, no van realitzar l'assimilació de sonoritat, lloc o mode d'articulació, formació d'africats i resil-labificació.

Taula 17. Resultats quantitatius d'errors/imprecisions de fenòmens de contacte

\begin{tabular}{|c|c|c|c|c|}
\hline Errors & Mots enquestats & Nivell inicial-bàsic & Nivell mitjà & Nivell alt \\
\hline \multirow{10}{*}{$\begin{array}{l}\text { Elisió d'oclusius } \\
\text { en coda (PA) }\end{array}$} & pot dir & $2 / 10$ & $1 / 5$ & 0 \\
\hline & fred terrible & 0 & $2 / 5$ & $1 / 4$ \\
\hline & Casa Batlló & 0 & 0 & $2 / 4$ \\
\hline & fet cabdal & $1 / 10$ & 0 & $1 / 4$ \\
\hline & setmana & $4 / 10$ & 0 & $2 / 4$ \\
\hline & advocat & $2 / 10$ & $3 / 5$ & $1 / 4$ \\
\hline & adquirir & 0 & $1 / 5$ & $1 / 4$ \\
\hline & pot gastar & $1 / 10$ & $1 / 5$ & 0 \\
\hline & dit petit & 0 & $3 / 5$ & 0 \\
\hline & set-cents dos & $2 / 10$ & $3 / 5$ & $1 / 4$ \\
\hline \multirow{5}{*}{$\begin{array}{l}\text { Manca d'assimilació } \\
\text { de sonoritat amb } \\
\text { pausa entre mots } \\
\text { (PA) }\end{array}$} & pot dir & $6 / 10\left(\left[\mathrm{t}|\mathrm{d}, \widehat{\mathrm{ts}}| \mathrm{d}, \mathrm{t}^{\mathrm{h}} \mid \mathrm{d}\right]\right)$ & $1 / 5([\widetilde{\mathrm{ts}} \mid \mathrm{d}])$ & 0 \\
\hline & admirar & $3 / 10\left[\mathrm{t}, \mathrm{t}^{\mathrm{h}}, \mathrm{s}\right]$ & 0 & $1 / 4([\theta])$ \\
\hline & adjectiu & $2 / 10([\mathrm{t} \mid \widehat{\mathrm{d}} 3])$ & 0 & 0 \\
\hline & Casa Batlló & $3 / 10\left[\mathrm{t}^{\mathrm{h}}, \widehat{\mathrm{ts}}, \mathrm{t}\right]$ & 0 & 0 \\
\hline & pot gastar & $\begin{array}{l}7 / 10\left(\left[\widetilde{\mathrm{t}^{\mathrm{s}}} \cdot \mathrm{g}, \widehat{\mathrm{ts}}\left|\mathrm{g}, \mathrm{t}^{\mathrm{h}}\right| \mathrm{g},\right.\right. \\
\mathrm{t} \mid \mathrm{g}])\end{array}$ & 0 & $1 / 4([\mathrm{t} \mid \mathrm{g}])$ \\
\hline
\end{tabular}




\begin{tabular}{|c|c|c|c|c|}
\hline $\begin{array}{l}\text { Manca d'assimilació } \\
\text { de lloc d'articulació } \\
\text { amb pausa entre mots } \\
\text { (AE) }\end{array}$ & $\begin{array}{l}\text { futbol [d.b] } \\
\text { dit petit } \\
\text { fet cabdal } \\
\text { pot gastar } \\
\text { advocat [d.b] } \\
\text { adquirir [t.k] }\end{array}$ & $\begin{array}{l}10 / 10 \\
9 / 10\left(\left[\mathrm{t} \cdot \mathrm{p}, \mathrm{t}^{\mathrm{h}} \cdot \mathrm{p}, \widehat{\mathrm{t}^{\mathrm{s}}} \cdot \mathrm{p}\right]\right) \\
9 / 10\left(\left[\mathrm{t} \cdot \mathrm{k}, \mathrm{t}^{\mathrm{h}} \cdot \mathrm{k}\right]\right) \\
9 / 10\left(\left[\mathrm{t} \cdot \mathrm{k}, \widehat{\mathrm{t}^{\mathrm{s}}} \cdot \mathrm{g}, \widehat{\mathrm{ts}} \mid \mathrm{g}, \mathrm{d} \cdot \mathrm{g},\right.\right. \\
\left.\left.\mathrm{t}^{\mathrm{h}}|\mathrm{g}, \mathrm{t}| \mathrm{g}\right]\right) \\
6 / 10 \\
10 / 10\end{array}$ & $\begin{array}{l}4 / 5 \\
2 / 5([\mathrm{t} . \mathrm{p}]) \\
4 / 5([\mathrm{t} . \mathrm{k}]) \\
4 / 5([\mathrm{~d} . \mathrm{g}]) \\
2 / 5 \\
4 / 5\end{array}$ & $\begin{array}{l}4 / 4 \\
4 / 4([\mathrm{t} \cdot \mathrm{p}]) \\
3 / 4([\mathrm{t} \cdot \mathrm{k}]) \\
2 / 4([\mathrm{t} . \mathrm{k} \\
\mathrm{t} \mid \mathrm{g}]) \\
3 / 4 \\
1 / 4\end{array}$ \\
\hline $\begin{array}{l}\text { Manca d'assimilació } \\
\text { de mode d'articulació } \\
\text { amb pausa entre mots } \\
\text { (AE) }\end{array}$ & $\begin{array}{l}\text { setmana [d.m] } \\
\text { admirar } \\
\text { segment [g.m] } \\
\text { signe [g.n] }\end{array}$ & $\begin{array}{l}6 / 10 \\
8 / 10\left(\left[\mathrm{~d} \cdot \mathrm{m}, \mathrm{t}^{\mathrm{h}} \cdot \mathrm{m}, \mathrm{t} \mid \mathrm{m}\right]\right) \\
10 / 10 \\
9 / 10\end{array}$ & $\begin{array}{l}5 / 5 \\
3 / 5([\text { d.m }]) \\
5 / 5 \\
3 / 5\end{array}$ & $\begin{array}{l}2 / 4 \\
3 / 4([\text { d.m }]) \\
3 / 4 \\
0\end{array}$ \\
\hline $\begin{array}{l}\text { Manca de resilla- } \\
\text { bificació i formació } \\
\text { d'africats amb pausa } \\
\text { entre mots }(\mathrm{PB})\end{array}$ & $\begin{array}{l}\text { set-cents dos [t.s] } \\
\text { set gegants } \\
\text { adjectiu }\end{array}$ & $\begin{array}{l}4 / 10 \\
10 / 10([\mathrm{t} . \mathrm{s}, \mathrm{d}|3, \mathrm{t}| \mathrm{d} 3, \\
\left.\left.\mathrm{t}^{\mathrm{h}} \mid \mathrm{d} 3\right]^{11}\right) \\
0\end{array}$ & $\begin{array}{l}0 \\
4 / 5 \quad([\mathrm{~d}|3, \mathrm{t}| \mathrm{d} 3, \\
\text { d.3] }) \\
2 / 5([\mathrm{~d} .3])\end{array}$ & $\begin{array}{l}1 / 4 \\
1 / 4([\mathrm{t} \mid \mathrm{d} z]) \\
0\end{array}$ \\
\hline
\end{tabular}

També van canviar el lloc d'articulació de [p, k] seguides per [s] en coda formant l'africada $[\widetilde{\mathrm{ts}}]$ o pronunciar $/ \mathrm{t}, \mathrm{d} /$ en coda com a [ $[\mathrm{ts}]$. Aquest tipus d'error no ha estat previst en l'estudi contrastiu.

Taula 18. Resultats quantitatius d'africació

\begin{tabular}{|l|l|l|l|l|}
\hline Errors & Mots enquestats & Nivell inicial-bàsic & Nivell mitjà & Nivell alt \\
\hline$[\mathrm{ps}]>[\widehat{\mathrm{ts}}]$ & naps & 0 & 0 & $1 / 4$ \\
& calbs & 0 & 0 & $1 / 4$ \\
\hline$[\mathrm{ks}]>[\widehat{\mathrm{ts}}]$ & mosaics & $2 / 10$ & 0 & $1 / 4$ \\
& calcs & $1 / 10$ & 0 & $1 / 4$ \\
\hline$/ \mathrm{d} /[\mathrm{d}]>[\widehat{\mathrm{ts}}]$ & pot dir & $3 / 10$ & $1 / 5$ & 0 \\
\hline$/ \mathrm{t} /[\mathrm{t} / \mathrm{p}]>[\widetilde{\mathrm{ts}}]$ & dit petit & $1 / 10$ & 0 & 0 \\
\hline
\end{tabular}

Finalment, considerant el currículum especial de la informant 19, que ha nascut a Catalunya i domina completament el català però utilitza freqüentment el xinès en la comunicació amb els familiars, s'ha revisat la seva pronunciació per saber quins problemes eren més persistents. S'ha notat que va presentar els següents errors: manca d'aproximantització a l'inici de la segona paraula d'un compost o després d'africat/fricatiu: Casa [b]atlló, mig[d]ia, set-cents [d] os; sonorització en posicions àtones: $c a[\mathrm{~d}]$ edral, tro[g] $a$; ultracorrecció: [d] roca; elisió d'oclusius a coda: naip, calb, addicció, fred terrible; escurçament d'oclusius en coda: $\operatorname{ver}[\mathrm{p}]$, au $\left.{ }^{\mathrm{g}}\right]$ ment; formació d'africat: calbs ${ }^{\star}$ ['kalts]. Aquests errors indiquen que els errors o imprecisions d'aspecte suprasegmental (casos Casa Batlló, migdia, set-cents dos) costen més de corregir, i la transferència del xinès pot ocórrer fins i tot quan el parlant tingui nivell nadiu. 


\subsection{Anàlisis globals}

Després d'analitzar detalladament la pronunciació dels informants, es realitzen les següents observacions globals.

Els errors detectats dels informants de diferents nivells del català mostren una tendència que s'adiu amb la teoria d'interllengua. És un procés dinàmic caracteritzat per la superació de problemes bàsics, aparició de nous problemes i la reducció de tipus i freqüència d'errors. La confusió d'oclusius sords i sonors es pot presentar durant tot el procés d'interllengua, però a cada etapa hi ha problemes principals que requereixen atenció especial: ensordiment i manca d'aproximantització pel nivell inicial-bàsic, ultracorrecció per nivells mitjà i alt. Els de nivell comparativament més alt redueixen aquests errors de confusió, però no els poden evitar, sobretot en pronunciació espontània. A més a més, els aprenents de nivell més baix presenten més variants incorrectes per a un mateix so o un mateix problema. Vegem l'assimilació de sonoritat obligatòria i l'assimilació de mode d'articulació optativa en el cas de /d/ en el mot admirar [əm.mi' ra] ([əd.mi' ra]): els informants de nivell alt van realitzar les pronúncies ${ }^{\star}[\theta . \mathrm{m}]$ i $[\mathrm{d} . \mathrm{m}]$ per $<\mathrm{dm}>$, mentre que els de nivell mitjà van realitzar ${ }^{\star}[\mathrm{m}, 1 . \mathrm{m}]$ i $[\mathrm{d} . \mathrm{m}]$, i els de nivell baix, ${ }^{*}\left[\mathrm{t}^{\mathrm{h}} . \mathrm{m}, \mathrm{t} \mid \mathrm{m}\right.$, r.m, s.m] i $[\mathrm{d} . \mathrm{m}]$.

Un altre error que cal esmentar és l'elisió de /g/ en obertura complexa <gu> /gw/ [gw, fw] (taula 15) que només van presentar els informants de nivell alt mentre no tenien dificultats d'articular aquests sons. Aquest fenomen, junt amb els errors de [ps, ks] > [ [ts] en coda (taula 18), indica la importància de vocalitzar amb cura malgrat el bon domini de la llengua per tal d'evitar errors espontanis.

\subsection{Propostes de millora $i$ estratègies didàctiques}

Tot i que en anglès es distingeixen els oclusius sords i sonors, i el fet que els aprenents sinòfons han après aquesta llengua abans del català, no es pot considerar aquesta llengua una referència eficaç per corregir la pronunciació del català, ja que fer la distinció d'aspiració i no aspiració d'oclusius a l'hora de parlar l'anglès no els causa gaire confusió ni malentesos. Això vol dir que molts xinesos parlen l'anglès sense poder distingir els oclusius sords i sonors.

La sonorització d'oclusius sords en posicions àtones no inicials o intervocàliques del xinès $(\$ 2.2)$ pot ser una referència per als alumnes que tinguin aquest hàbit de pronunciació a l'hora de practicar els oclusius sonors, però no es pot fer servir per aquells que no tinguin costum de sonorització.

Tot i això, podem trobar alguns mètodes per practicar els oclusius sonors; un és començar amb les paraules que tinguin $[b, d, g]$ en posicions àtones precedides de $[m, n, n]$, respectivament, com ara la Rambla, setembre, tomba...; entendre, condició, rotunda...; llengua, ungla, enganyar. En aquests tipus de paraules els plecs glòtics comencen a vibrar abans d'obrir l'oclusió. El fet que els informants sonoritzessin freqüentment $[\mathrm{p}, \mathrm{t}]$ precedits de $[\mathrm{m}, \mathrm{n}]$ (vegeu la taula 12) però que presentessin pocs casos d'ensordiment de $[\mathrm{b}, \mathrm{d}, \mathrm{g}]$ en el mateix context (vegeu la taula 6: novembre, divendres, triangle) pot ser una evidència que presagia l'eficàcia d'aquest mètode de pràctica. Mentrestant, caldria reduir l'esforç a l'hora d'alliberar l'oclusió, ja que l'explosió dels oclusius sonors no ha de ser tan forta com la dels sords (Quilis 1993: 66; Quilis ${ }^{10} 2010 / 1997: 21$; Cao 2007: 97; Wang 2019: \$3.2.2.2). Un cop dominada la pronunciació dels oclusius en el context àton i post-nasal, es poden estendre els exercicis als contextos de síl-labes inicials o tòniques.

Els exercicis dels aproximants $[\beta, \gamma, \gamma]$ es poden realitzar després dels de $[b, d, g]$, sempre procurant suavitzar l'articulació d'aquests.

Per corregir l'afegitó de vocals curtes o de durada normal entre l'oclusiu i el líquid, podrien intentar articular més ràpidament els oclusius per evitar les vocals afegides. 
Pel que fa a l'elisió de [b, d, g] en coda (tipus verbs * ['bers], fluid *['fluj], porc * ['por]), es pot animar els aprenents que articulin els sons clarament sense preocupant-se del possible afegitó de vocals curtes al seu darrere, perquè en comparació amb l'elisió, aquest accent estranger és un problema de menys importància i podrà corregir-se amb l'adquisició de fluïdesa. Pel cas

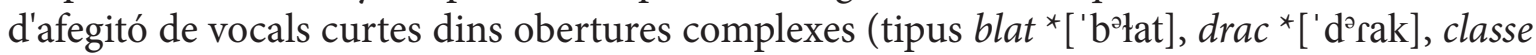
*['k’la.sə]), similarment, tampoc no s'hauria de considerar un mal senyal.

A part de l'esforç de correcció, la pràctica al vocalitzar també és importantíssima. Es proposaria practicar amb onomatopeies, parelles mínimes i embarbussaments catalans. Les onomatopeies i parelles mínimes són recomanables per als aprenents de nivell inicial-bàsic que necessiten dominar la distinció sord-sonor en paraules aïllades, mentre que els embarbussaments són útils per als de nivell intermedi-alt, etapa en què necessiten reforçar la pronunciació en contextos complexos. Tot seguit es donen uns exemples.

1. Onomatopeies:

tic-tac, toc-toc, bub-bub, cric-crac, gloc-gloc, xip-xap, clap-clap, patatxap, quiquiriquic...

2. $/ \mathrm{p}-\mathrm{b} / \mathrm{:}$

pas - vas, prendre - vendre, pinya - vinya, por - bo

plau - blau, prou - brou, plat blau pla ple de pebre

A Ponts pocs i bons, i encara els que són bons no són de Ponts.

Babau, veu vi bo i viu bé.

Vinc al bosc i busco vesc i visc del vesc que busco al bosc.

3. $/ \mathrm{t}-\mathrm{d} /$ :

tos - dos, tia - dia; boter - poder; quatre - quadre, centre - cendra

El didot ha dut un didal a la dida, li ha dat al dit i li ha dit la dita: "didal és dot".

4. $/ \mathrm{k}-\mathrm{g} /$ :

col - gol, cas - gas, calze - galze; vaca - vaga;

classe - glaça, club blaugrana, gran - cranc, grec - crec

Digui-li que digui que sigui l'indi xic qui li tingui la bici i qui l'infli.

5. Oclusius a coda:

El que et dec, Dídac, et dic que és poc, i com et dic, no sóc ric, si no t'ho pago de cop, t'ho pagaré a poc a poc.

Last but not least, no s'ha d'oblidar la importància de l'autoconsciència dels aprenents a corregir-se i parlar amb cura, sobretot a l'hora de tractar el problema d'ultracorrecció i evitar errors espontanis presentats en les taules 15 i 18. També és important començar la correcció de la pronunciació com més aviat possible, des del primer dia de l'aprenentatge, diguem, per evitar la fossilització dels errors de pronunciació.

\section{Conclusions}

Els oclusius de català /p-b/, /t-d/, /k-g/ i els del xinès /p- $\mathrm{p}^{\mathrm{h}} /, / \mathrm{t}-\mathrm{t}^{\mathrm{h}} /, / \mathrm{k}-\mathrm{k}^{\mathrm{h}} /$ es diferencien tant d'inventari i tret distintiu com de distribució en la síllaba. Per aquesta raó, els aprenents xinesos d'aquesta llengua romànica poden presentar diversos problemes de pronunciació.

El tret distintiu de sonoritat del català i l'articulació dels oclusius sonors /b, d, g/ són els primers obstacles que s'han d'afrontar. Després, la complexitat de l'estructura sil-làbica del català 
(del model $\mathrm{C}_{0-2} \mathrm{VC}_{0-3}$ ), en comparació amb la del xinès (del model $\mathrm{C}_{0-1} \mathrm{VC}_{0-1 \text { (semivocal, nasal dental o }}$ velar), ha plantejat certes dificultats als aprenents xinesos, especialment les obertures complexes "oclusiu $+[\mathrm{l} / \mathrm{r}]$ " i codes complexes amb oclusius implicats.

Els errors de pronunciació que presenten els aprenents xinesos són conformes a la teoria d'interllengua. Tenen diferents tipus de problemes en distintes etapes d'aprenentatge: els de l'àmbit segmental es presenten més freqüentment en l'etapa inicial i bàsic, mentre que els de l'àmbit suprasegmental sil-làbic apareixen durant tot el procés d'aprenentatge i costen més de superar; a mesura que es millora el nivell de l'idioma, es va reduint la freqüència d'un mateix problema i el nombre de les variants incorrectes per a un mateix so.

Durant les activitats didàctiques, a més d'aprofitar materials diversos per corregir la pronunciació, és necessari començar la correcció com més aviat possible, d'una banda; i prestar atenció contínua i prendre l'autoconsciència de pronunciar amb cura per reduir la freqüència d'errors i evitar desviacions espontànies causades per vocalització descurada.

\section{Bibliografia}

Banov, I. K. (2014). The production of Voice onset time in voiceless stops by Spanish-English natural bilinguals. Treball de màster. Brigham Young University.

Bassa, R. (2015). Llenguatge oral i jocs de llengua a la primària infància. Aplicacions didàctiques, dins R. Bassa (coord.) \& L. Pastor (dir.), El llenguatge oral i escrit a l'escola: bones pràctiques. Editorial UOC.

Bonet, E. \& Lloret, M.-R. (1998). Fonologia catalana. Ariel.

Bonet, E., Lloret, M.-R. \& Mascaró, J. (22000/1997). Manual de transcripció fonètica. UAB, Servei de Publicacions.

Butler, B. A. (2014). Deconstructing the Southeast Asian sesquisyllable: a gestural account. Tesi doctoral. Cornell University.

Cao, Y. (2007). Un estudio contrastivo de los fonemas oclusivos entre español y chino. Reflexiones sobre la enseñanza de la fonética española a estudiantes chinos, México y la Cuenca del Pacífico, 10 (28), 91-98.

Casas-Tost, H. \& Rovira-Esteva, S. (ed.) (2015). Guia d'estil per al tractament de mots xinesos en català. Generalitat de Catalunya, Departament de Cultura.

Celce-Murcia, M., Brinton, D. M. \& Goodwin, J. M. (1996). Teaching pronunciation: A reference for teachers of English to speakers of other languages. Cambridge University Press.

Chao Y.-R. (1968). A grammar of spoken Chinese. University of California.

Chao, Y.-R., Wu, Z. \& Zhao, X. (ed.). (2002). Zhao Yuen-Ren Yuyanxue Lunwenji. Beijing: Shangwu Yinshuguan.

Chen, L., Chao K.-Y. \& Peng J.-F. (2007). VOT productions of word-initial stops in Mandarin and English: A cross-language study, ROCLING 2007 Poster Papers, 303-317. Taipei, Taiwan.

Dols, N. ( $\left.{ }^{4} 2008 / 2002\right)$. Fenòmens en grups consonàntic, dins J. Solà, M.-R. Lloret, J. Mascaró \& M. Pérez Saldanya (dir.), Gramàtica del català contemporani. Vol. 1: Introducció. Fonètica i fonologia. Morfologia. 4a edició (definitiva), 319-343. Empúries.

Duanmu, S. (2007/2000). The phonology of standard Chinese. Oxford University Press.

- (2011). Chinese syllable structure, dins M. v. Oostendorp, C. J. Ewen, E. Hume \& K. Rice (ed.), The Blackwell companion to phonology, Vol. V: Phonology across languages, 2754-2777. Blackwell. 
Gimson, A. C. ( $\left.{ }^{3} 1980 / 1962\right)$. An introduction to the pronunciation of English. Edward Arnold. Institut d'Estudis Catalans (2016). Gramàtica de la llengua catalana.

Jensen, J. T. (1993). English phonology. John Benjamins.

Jiménez, J. (1999). L'estructura sil-làbica del català. Institut Interuniversitari de Filologia Valenciana / Publicacions de l'Abadia de Montserrat.

Julià i Muné, J. (1981). Estudi contrastiu dels oclusius de l'anglès i del català. Un experiment acústic, Estudi general, I (2), 75-85.

Julià-Muné, J. (2005). Fonètica aplicada catalana. Dels fonaments a les aplicacions de les ciències fonètiques. Ariel.

— $\left({ }^{4} 2008 / 2002\right)$. Els sons del català, dins J. Solà, M.-R. Lloret, J. Mascaró \& M. Pérez Saldanya (dir.), Gramàtica del català contemporani, Vol. 1: Introducció. Fonètica i fonologia. Morfologia. 4a edició (definitiva), 37-87. Empúries.

- (2009). Les llengües de la Xina. El contrast fonètic i l'adaptació al català de l'onomàstica xinesa, dins J. Julià-Muné (ed.), Visions de la Xina: cultura multimil-lenària, 59-80. Institut d'Estudis Ilerdencs.

- (2011). La transferència fonotàctica en l'aprenentatge d'L2: el cas de parlants de mandarí que aprenen català, dins M.-R. Lloret \& C. Pons-Moll (ed.), Noves aproximacions a la fonologia i la morfologia del català: Volum d'homenatge a Max W. Wheeler, 295-319. Institut Interuniversitari de Filologia Valenciana.

- (2014). Catalan, dins C. Fäcke (ed.), Manual de Language acquisition, 345-370. Berlín: De Gruyter.

- (2017). Propuesta de adaptación ortológica de la onomástica china al español, Onomàstica 3 (Barcelona), 29-68.

- (2019). L'estandardització del català i del xinès. Processos paral.lels? Edicions de la Universitat de Lleida.

Kenworthy, J. (1987). Teaching English pronunciation. Longman.

Klatt, D. H. (1975). Voice Onset Time, frication, and aspiration in word-initial consonant clusters, Journal of Speech and Hearing Research, vol. 18, 686-706.

Lin, Y.-H. (2007). The Sounds of Chinese. Cambridge University Press.

Lisker, L., Abramson, A. S. (1964). A cross-language study of voicing in initial stops: acoustical measurements, Word, 20, 384-422.

Liu, Z. (2016). Exploring cross-linguistic influence: Perception and production of L1, L2 and L3 bilabial stops by Mandarin Chinese speakers. Treball Fi de Màster. Universitat Autònoma de Barcelona.

Lloret, M.-R. ( $\left.{ }^{4} 2008 / 2002\right)$. Estructura sil-làbica, dins J. Solà, M.-R. Lloret, J. Mascaró \& M. Pérez Saldanya (dir.), Gramàtica del català contemporani, Vol. 1: Introducció. Fonètica i fonologia. Morfologia. 4a edició (definitiva), 196-249. Empúries.

— (2011). La fonologia del català. Col-lecció El que sabem de... Departament d'Edicions Educatives de Grup Promotor / Santillana Educación, S.L.

McMahon, A. (2002). An introduction to English phonology. Edinburgh University Press.

Mallart, J. (2000). La interllengua en l'aprenentatge d'una L2, dins J. Julià i Muné (ed.), L'ensenyament del català com a L2. De la teoria a la pràctica, 73-91. Universitat de Lleida. 
Palmada, B. ( $\left.{ }^{4} 2008 / 2002\right)$. Fenòmens assimilatòria, dins J. Solà, M.-R. Lloret, J. Mascaró \& M. Pérez Saldanya (dir.), Gramàtica del català contemporani, Vol. 1: Introducció. Fonètica i fonologia. Morfologia. 4a edició (definitiva), 251-270. Empúries.

Polanco Roig, Lluís B. (ed. literari) (2019). Proposta de transcripció del xinès al català: (Acord del 9 de març de 2018). Institut d'Estudis Catalans, Secció Filològica.

Quilis, A. (1993). Tratado de fonología y fonética españolas. Gredos.

- $\left({ }^{10} 2010 / 1997\right)$. Principios de fonología y fonética españolas. Arco Libros, S. L.

Roach, P. ( $\left.{ }^{4} 2009 / 1983\right)$. English phonetics and phonology: A practical course. Cambridge University Press.

Santos Gargallo, I. (1993). Análisis contrastivo, análisis de errores e interlengua en el marco de la lingüística contrastiva. Síntesis.

Selinker, L. (1969). Language transfer, General linguistics, 9, 67-92.

- (1972). Interlanguage, International Review of Applied Linguistics in Language Teaching, 10 (1-4), 209-232.

Taehong, C. i Ladefoged, P. (1999). Variation and universals in VOT: Evidence from 18 languages. Journal of Phonetics, 27, 207-229.

Wang, L. (2018). Estudio contrastivo de la estructura silábica del catalán y del chino estándares y de las implicaciones segmentales más relevantes para los estudiantes sinófonos, dins $\mathrm{M}$. D. Ferro, G. Vaamonde et al. (ed.), Actas do XIII Congreso Internacional de Lingüística Xeral, 928-933. Universidade de Vigo.

- (2019). Estudi contrastiu de l'estructura sil-làbica del català i del xinès estàndards i de les implicacions segmentals més rellevants per als aprenents sinòfons. Tesi doctoral. Barcelona: Universitat de Barcelona.

Wu, Z. (ed.) (1992). Xiandai Hanyu Yuyin Gaiyao. Huayu Jiaoxue Chubanshe.

Espais web:

Carrera-Sabaté, J., Pons-Moll, C. \& Solà-Cortassa, J. (2014). Sons del català. Pàgina web: $<$ http://www.ub.edu/sonscatala/ca/presentacio $>$.

Carrera-Sabaté, J.\& Prieto, P. (coord.) (2012-2019). Guies de Pronunciació del català. Pàgina web: <http://www.ub.edu/guiesdepronunciacio >. 